Round-Robin Testing of a Soleq EVcort According to the SAE J1634 Test Procedure Dated May 1993
G. H. Cole
RERTVED

MN 22 ใ3O

OSTI

Engineering

Laboratory

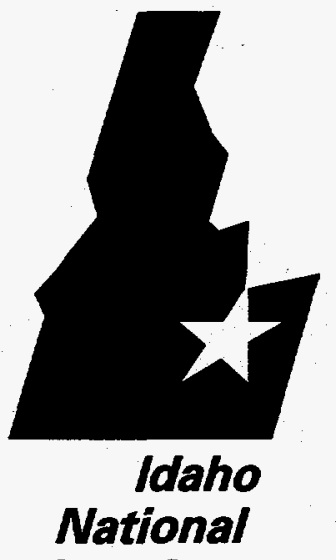

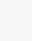




\section{DISCLAIMER}

This report was prepared as an account of work sponsored by an agency of the United States Government. Neither the United States Government nor any agency thereof, nor any of their employees, makes any warranty, express or implied, or assumes any legal liability or responsibility for the accuracy, completeness, or usefuiness of any information, apparatus, product or process disclosed, or represents that its use would not infringe privately owned rights. References herein to any specific commercial product, process, or service by trade name, trademark, manufacturer, or otherwise, does not necessarily constitute or imply its endorsement, recommendation, or favoring by the United States Government or any agency thereof. The views and opinions of authors expressed herein do not necessarily state or reflect those of the United States Government or any agency thereof. 


\title{
Round-Robin Testing of a Soleq EVcort According to the SAE J1634 Test Procedure Dated May 1993
}

\author{
G. H. Cole
}

April 1996

Prepared for the

U. S. Department of Energy

Assistant Secretary for Energy Efficiency and Renewable Energy (EE)

Under DOE Idaho Operations Office

Contract DE-AC07-94D13223 
7uaminop

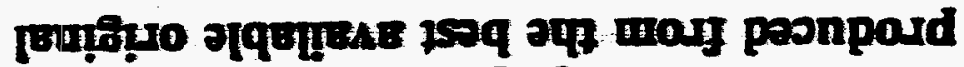

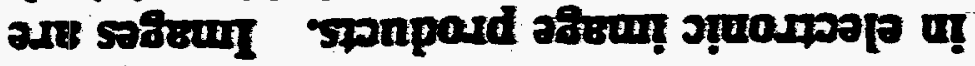

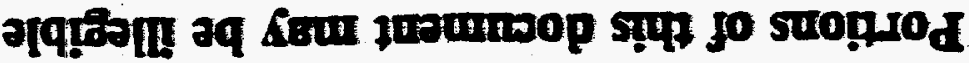
บENTIDSTa 


\section{EXECUTIVE SUMMARY}

The Society of Automotive Engineers Recommended Practice, SAE J1634, "Electric Vehicle Energy Consumption and Range Test Procedure", May 1993, describes a standard method of determining the range and energy consumption for electric vehicles. Consequent to the U. S. Department of Energy's (DOE) rulemaking released on February 4, 1994, the EPA is currently considering factoring electric vehicles into the Corporate Average Fuel Economy (CAFE) calculations using the SAE J1634 procedure. The purpose of this project is to provide information regarding the suitability of this recommended practice for determining the energy economy value to be factored into the CAFE. Issues leading to possible inconsistent results (such as the repeatability of the procedure, thoroughness of the procedure's methods, and variance between different laboratories using different dynamometers) need to be resolved prior to passing legislation which will mandate use of this test in determining the electric vehicle CAFE credit. To this end, separate tests were performed on a Soleq EVcort vehicle by the INEL, the EPA, Ford Motor Company, Southwest Research Institute, and the California Air Resources Board using their own facilities and personnel. Acceptable departures from the driving profile prescribed by SAE J1634 are not well defined. This deficiency in the procedure is even more noticeable due to the EVcort's marginal acceleration performance.

At the conclusion of the test program, significant observations of laboratory personnel and conclusions reached via analysis of test data are the following:

- Battery ampere-hour capacity can be measured effectively by discharging the battery in the vehicle on the chassis dynamometer by manually modulating the vehicle accelerator pedal to maintain a near constant current condition.

- Determining when the vehicle has reached the test termination criterion (departure from speed tolerance for two seconds) is difficult to determine without a driver's aid display which shows these limits on a second-by-second basis.

- The procedure for dynamometer calibration referenced by the SAE J1634 procedure does not apply to electric dynamometers although the procedure recommends the use of a dynamometer of this type. Each laboratory used its own standard calibration procedure. 
- Results agreed well between laboratories for net vehicle DC energy consumption and gross vehicle DC energy consumption. However, system DC energy consumption and system AC energy consumption results varied significantly. Test data supporting this conclusion are shown in Figure ES-1. Variations in battery charging behavior are hypothesized to be the major contributor to this phenomenon.

- The measured vehicle range varied significantly between the test laboratories (see Figure ES-2). Ambiguities in the test procedure's instructions as to the termination criteria and the lack of suitable driver's aid displays at the test sites are believed to be the major cause of these variations.

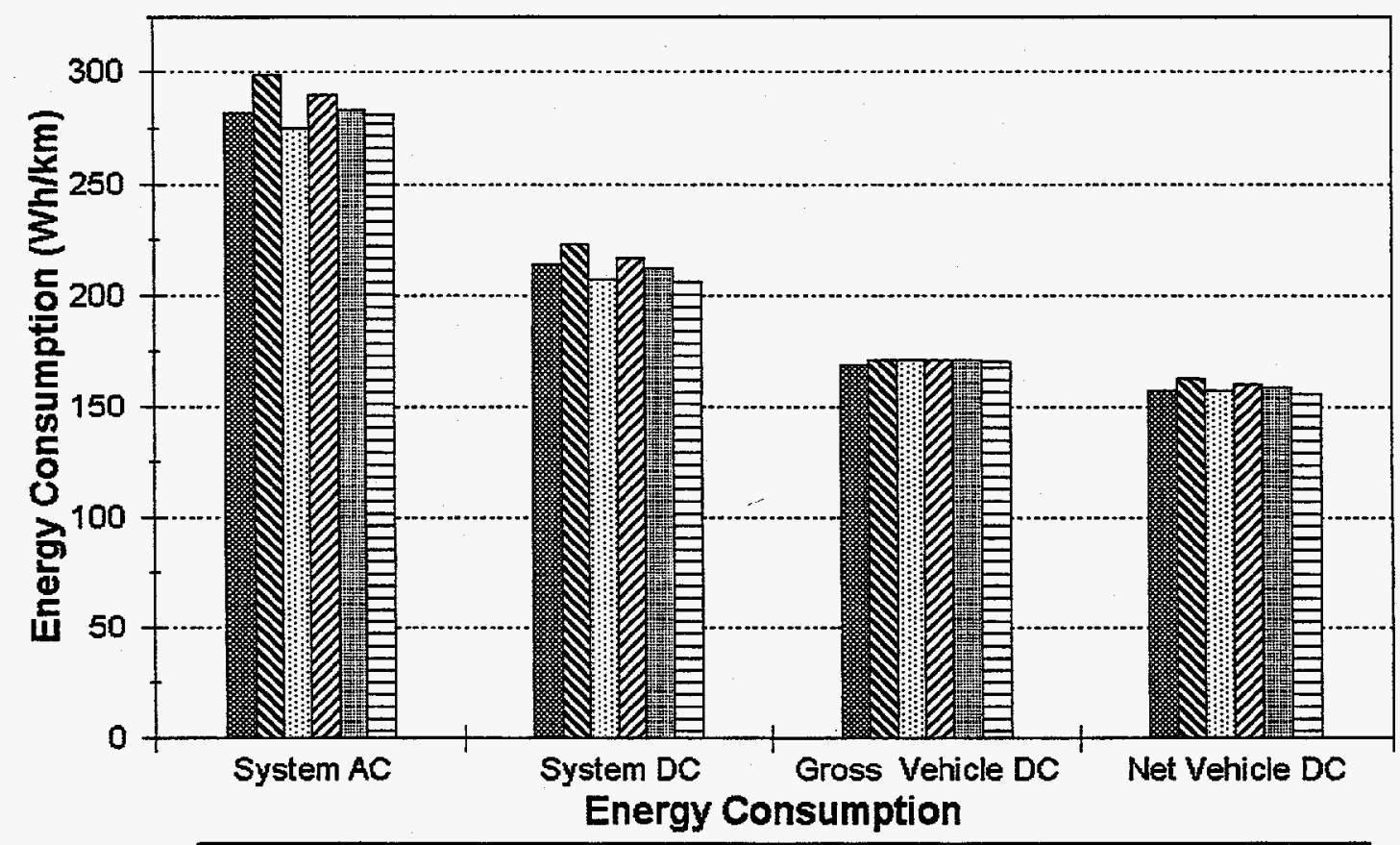

INEL-Clayton Electric Dyno

EPA-Clayton Hydrokinetic Dyno

\rceil EPA-Horiba Electric Dyno

FWRI - Clayton Hydrokinetic Dyno

Ford-Clayton Hydrokinetic Dyno CARB - Clayton Hydrokinetic Dyno

Figure ES-1. Comparison of energy consumption measured at each test site. 


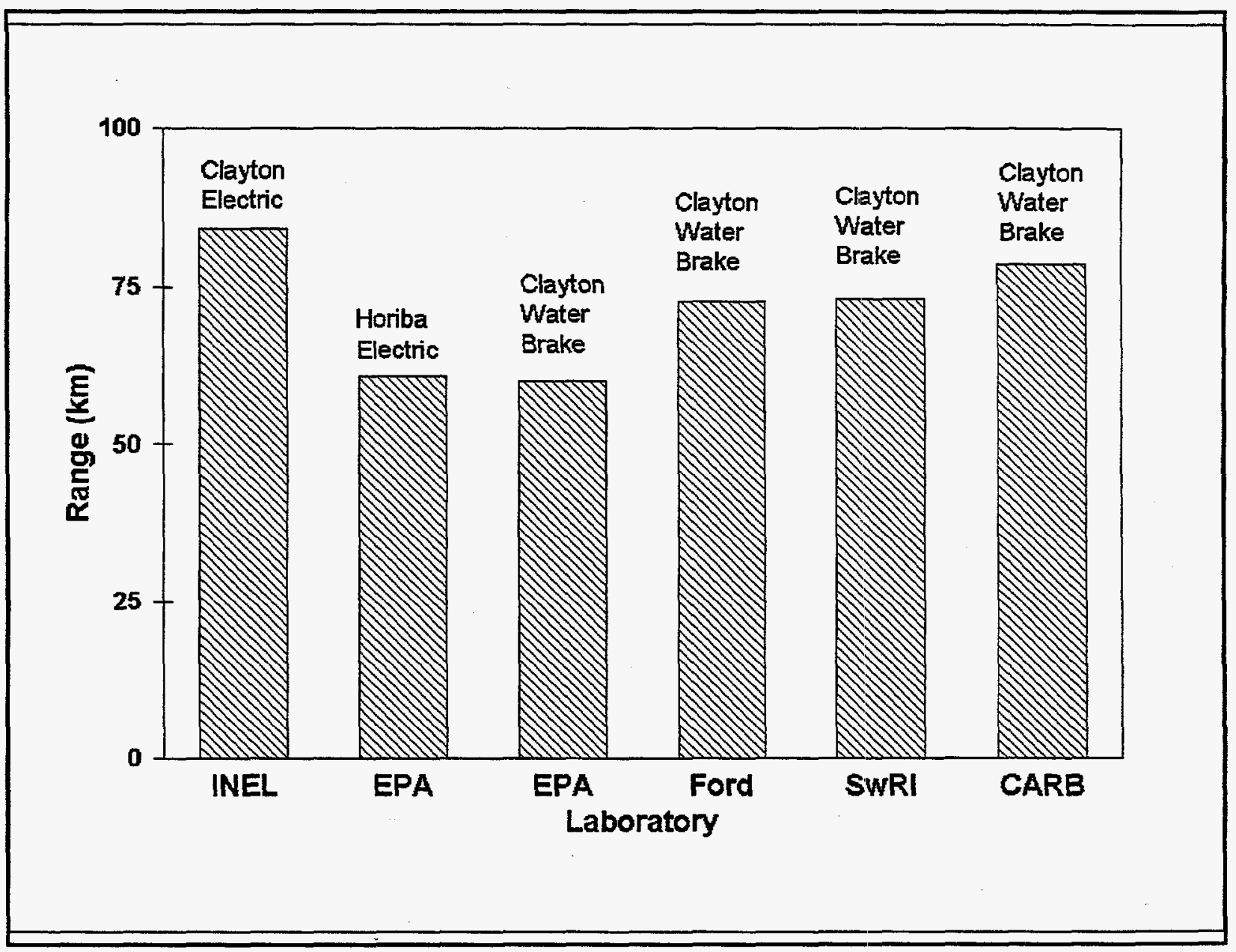

Figure ES-2. Comparison of vehicle range measured at each test site. 


\begin{abstract}
A "round-robin" test program was conducted by the Idaho National Engineering Laboratory (INEL) to determine the suitability of the Society of Automotive Engineers Recommended Practice, SAE J1634, "Electric Vehicle Energy Consumption and Range Test Procedure," for future Environmental Protection Agency (EPA) regulations. A common test vehicle (1988 Soleq EVcort) was tested according to the procedure at five different laboratories using six different chassis dynamometers. Comments are made regarding the adequacy of the procedure, and data (energy consumption and range) from each of the laboratories are presented.
\end{abstract}





\section{CONTENTS}

Executive Summary $\ldots \ldots \ldots \ldots \ldots \ldots \ldots \ldots \ldots \ldots \ldots \ldots \ldots$ ES-1

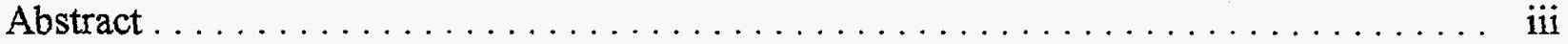

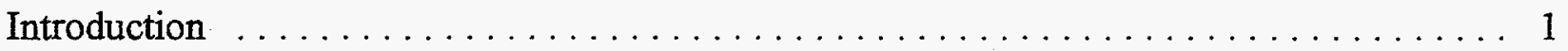

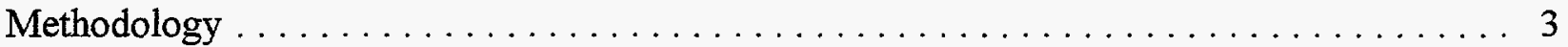

SAE J1634 Test Description $\ldots \ldots \ldots \ldots \ldots \ldots \ldots \ldots \ldots \ldots \ldots \ldots \ldots$

Coastdown Analysis for Dynamometer Calibrations $\ldots \ldots \ldots \ldots \ldots \ldots \ldots \ldots$

Round-Robin Test Vehicle Preparation \& Battery Capacity Verification . . . . . . . . . . 17

Data Acquisition System Comparison . . . . . . . . . . . . . . . . . . . . . . . . . . . . . 19

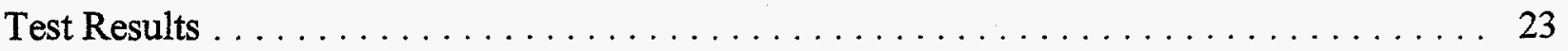

Idaho National Engineering Laboratory $\ldots \ldots \ldots \ldots \ldots \ldots \ldots \ldots \ldots \ldots$

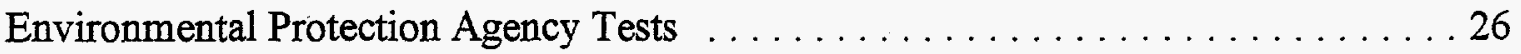

Ford Motor Company Tests $\ldots \ldots \ldots \ldots \ldots \ldots \ldots \ldots \ldots \ldots \ldots \ldots \ldots$

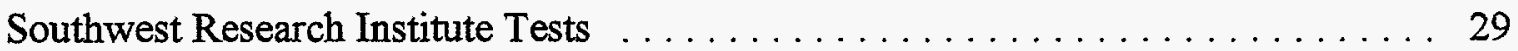

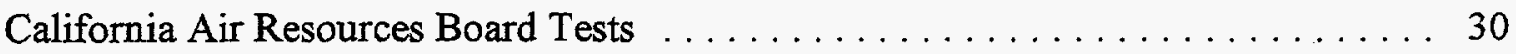

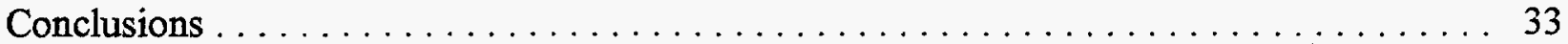

Additional Observations Made During Testing $\ldots \ldots \ldots \ldots \ldots \ldots \ldots \ldots \ldots$

\section{FIGURES}

ES-1 Comparison of energy consumption measured at each test site . . . . . . . . . E ES-2

ES-2 Comparison of vehicle range measured at each test site . . . . . . . . . . ES-3

1. Diagram of VDAS instrumentation set-up for the EVcort test vehicle $\ldots \ldots \ldots . \ldots 7$

2. Speed-time coastdown curves used for dynamometer calibrations . . . . . . . 16

3. Comparison of traction battery voltage measured using two different

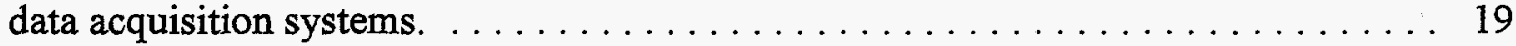

4. Comparison of traction battery current measured using two different

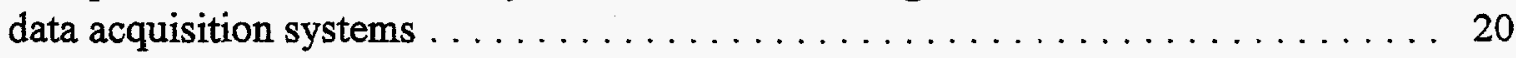


5. Comparison of vehicle speed measured using two different

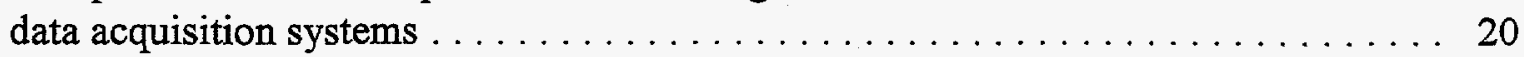

6. Comparison of energy consumption measured at each test site . . . . . . . . . . 34

7. Comparison of vehicle range measured at each test site $\ldots \ldots \ldots \ldots \ldots \ldots$

\section{TABLES}

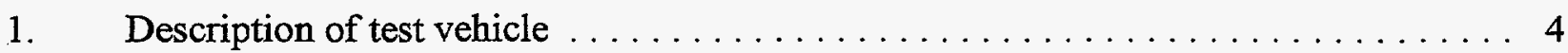

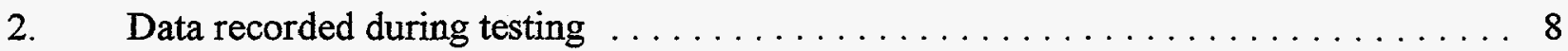

3. Derived coastdown times for each inertia weight $\ldots \ldots \ldots \ldots \ldots \ldots \ldots \ldots$

4. Comparison of measurements made with INEL's LDAS and the VDAS . . . . . . 21

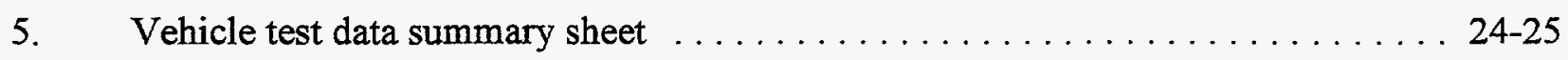

6. Results of tests conducted on the INEL Clayton electric dynamometer . . . . . . . 26

7. Results of tests conducted on EPA's Clayton dynamometer . . . . . . . . . . 27

8. Results of tests conducted on EPA's Horiba dynamometer $\ldots \ldots \ldots \ldots \ldots 28$

9. Results of test conducted on Ford's Clayton dynamometer . . . . . . . . . . . . . 29

10. Results of tests conducted on SwRI's Clayton dynamometer ............. 30

11. Results of tests conducted on CARB's Clayton dynamometer $\ldots \ldots \ldots \ldots \ldots . \ldots 31$

12. System energy economy and overall charger efficiency for

SAE J1634 energy economy tests at all test sites $\ldots \ldots \ldots \ldots \ldots \ldots \ldots \ldots \ldots$

\section{APPENDICES}

A. Letter Report from Environmental Protection Agency . . . . . . . . . . . . . . . A-1

B. Letter Report from Ford Motor Company $\ldots \ldots \ldots \ldots \ldots \ldots \ldots \ldots \ldots$ B-1

C. Letter Report from Southwest Research Institute $\ldots \ldots \ldots \ldots \ldots \ldots \ldots$ C-1

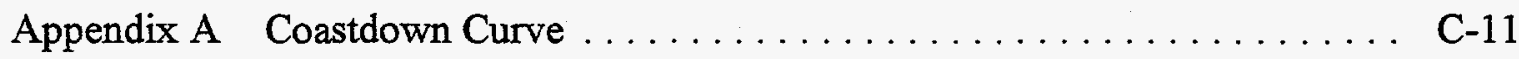

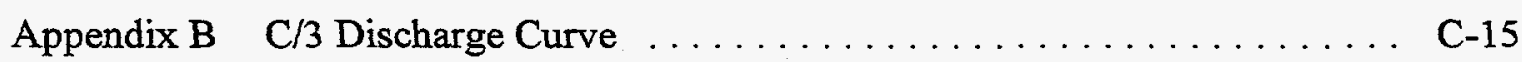

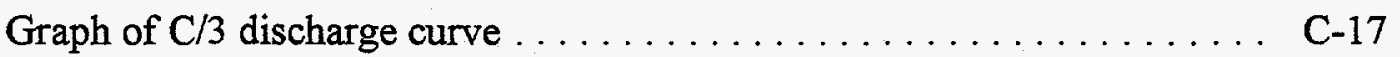

Photograph of computer data analysis $\ldots \ldots \ldots \ldots \ldots \ldots \ldots \ldots$ C-18 


\section{INTRODUCTION}

The Society of Automotive Engineers Recommended Practice, SAE J1634,"Electric Vehicle Energy Consumption and Range Test Procedure", May 1993, describes a standard method of determining the range and energy consumption for electric vehicles. Consequent to the DOE's rulemaking released on February 4, 1994, the EPA is currently considering factoring electric vehicles into the CAFE calculations using the SAE J1634 procedure. The purpose of this project is to provide information regarding the suitability of this recommended practice for determining the energy economy value to be factored into the CAFE. Issues leading to possible inconsistent results (such as the repeatability of the procedure, thoroughness of the procedure's methods, and variance between different laboratories using different dynamometers) need to be resolved prior to passing legislation which will mandate use of this test in determining the electric vehicle CAFE credit. To this end, separate tests were performed by the INEL, the EPA, Ford Motor Company, Southwest Research Institute, and the California Air Resources Board using their own facilities and personnel on a common vehicle (a Soleq EVcort). 

. . .

7

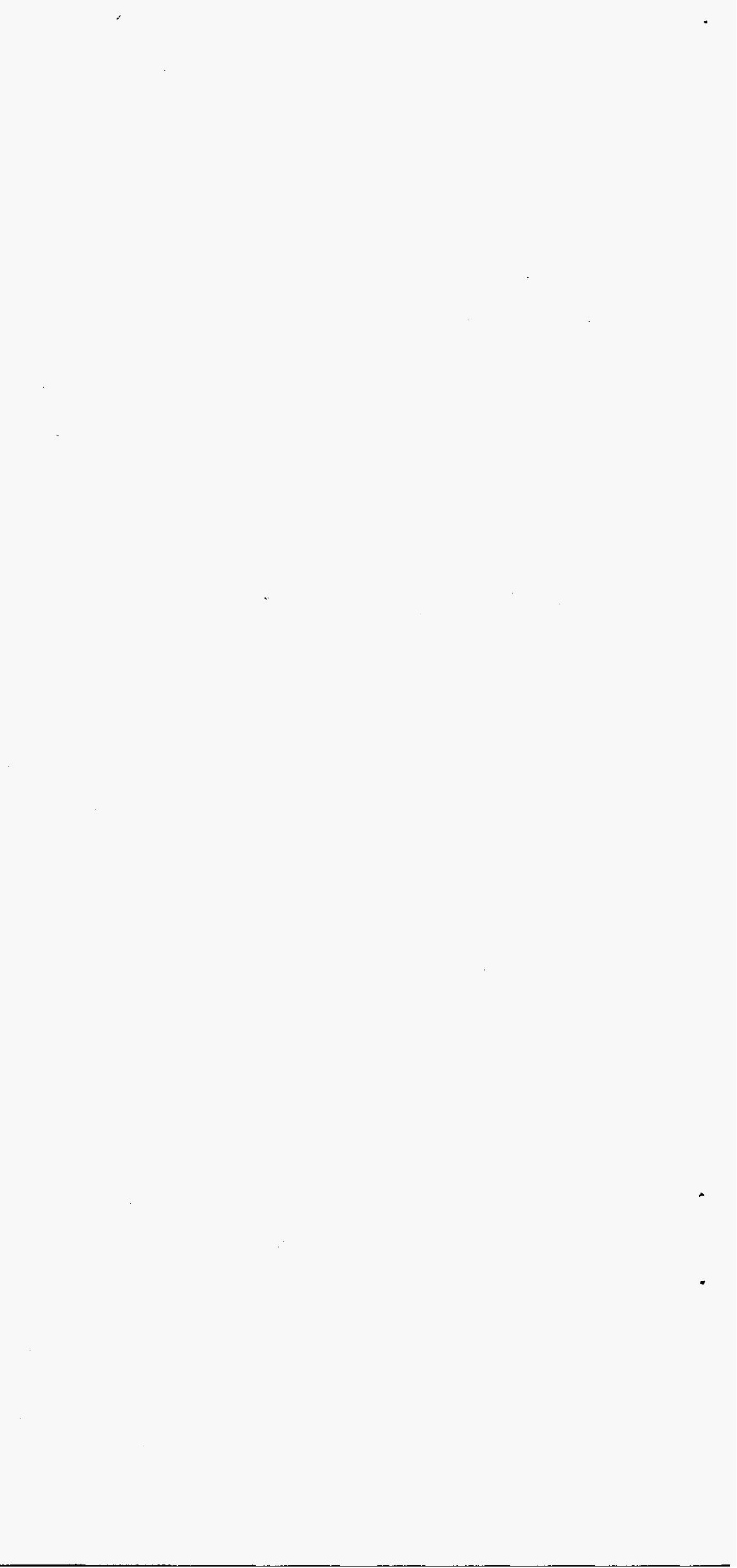




\section{METHODOLOGY}

The method of investigating used in this project is straightforward. The procedure, executed at five laboratories, involved six different dynamometers. To the extent possible, variables which were expected to contribute to variations in test results were held constant across each test site. Additionally, in order to fairly evaluate the clarity of SAE J1634, each test facility interpreted the procedure independently, and no central resolution team for unclear issues was formed. In effect, each laboratory was free to conduct the tests according to the procedure as they felt best. Each laboratory implemented its own standard operating procedures for dynamometer calibration and operation.

The major controlled variable is the test vehicle. The vehicle chosen for this project was a Ford Escort converted to electric propulsion by Soleq Corporation. This vehicle was loaned to the INEL for the purposes of this investigation by Arizona Public Service Company of Phoenix, AZ. Its salient characteristics are given in Table 1. 
Table 1. Description of test vehicle.

\begin{tabular}{|cl|}
\hline $\begin{array}{c}\text { Vehicle } \\
\text { Propulsion System }\end{array}$ & \\
Motor & Separately excited DC \\
Type & $32 \mathrm{~kW} @ 98 \mathrm{~V}, 400 \mathrm{~A}, 1600 \mathrm{rpm}$ \\
Peak Power & $6000 \mathrm{rpm}$ \\
Maximum Speed & $191 \mathrm{~N}-\mathrm{m}$ \\
Maximum Torque & General Electric Corp. \\
Manufacturer & \\
Controller & Soleq (U.S. Patent 4322667) \\
Manufacturer & 400 A \\
Maximum Current & \\
Transmission & 5-speed manual \\
Type & Ford Motor Company \\
Manufacturer & \\
Battery & Sealed lead-acid \\
Type & 18 \\
No. of Modules & Sonnenschein \\
Manufacturer & DF6V160 \\
Model & 138 Ah \\
Capacity (C/3) & \\
\hline
\end{tabular}

The vehicle was chosen for its demonstrated reliability and repeatability on previous tests performed at the INEL. The battery for these tests was chosen for its demonstrated long cycle life and consistent performance on tests previously performed at the INEL battery laboratory 
(see Hardin, J. E., "Laboratory Testing And Post-Test Analysis Of Sonnenschein DF 6V-160 6Volt Traction Battery", EGG-EP-10746, September 1993).

The instrumentation common to all tests at each of the participating laboratories was calibrated according to NIST-traceable standards and supplied by INEL. The INEL-developed Versatile Data Acquisition System (VDAS) was used by all sites to record second-by-second results for later analysis of test variances.

The two significant uncontrolled variables were the dynamorneters which were used by the participating laboratories and the interpretation of the test procedure itself. Dynamometer types included twin-roll electric, single-roll electric, and twin-roll water brake. As mentioned previously, no additional definition of the test procedure was be specified to the laboratories conducting the tests. 
, 


\section{INSTRUMENTATION AND MEASUREMENTS}

The INEL Versatile Data Acquisition System was used to record all measurements during tests performed at the four test sites. Readings of each of the measurements were sampled at $10 \mathrm{~Hz}(100 \mathrm{~ms})$ and logged at one-second intervals during driving portions of the test program. Charge data were logged at 1-minute intervals. Fifteen channels of data are logged during driving cycles and 13 channels were logged during periods of battery charging. Figure 1 shows a diagram of the instrumentation set-up. These measurements are identified in Table 2 ..

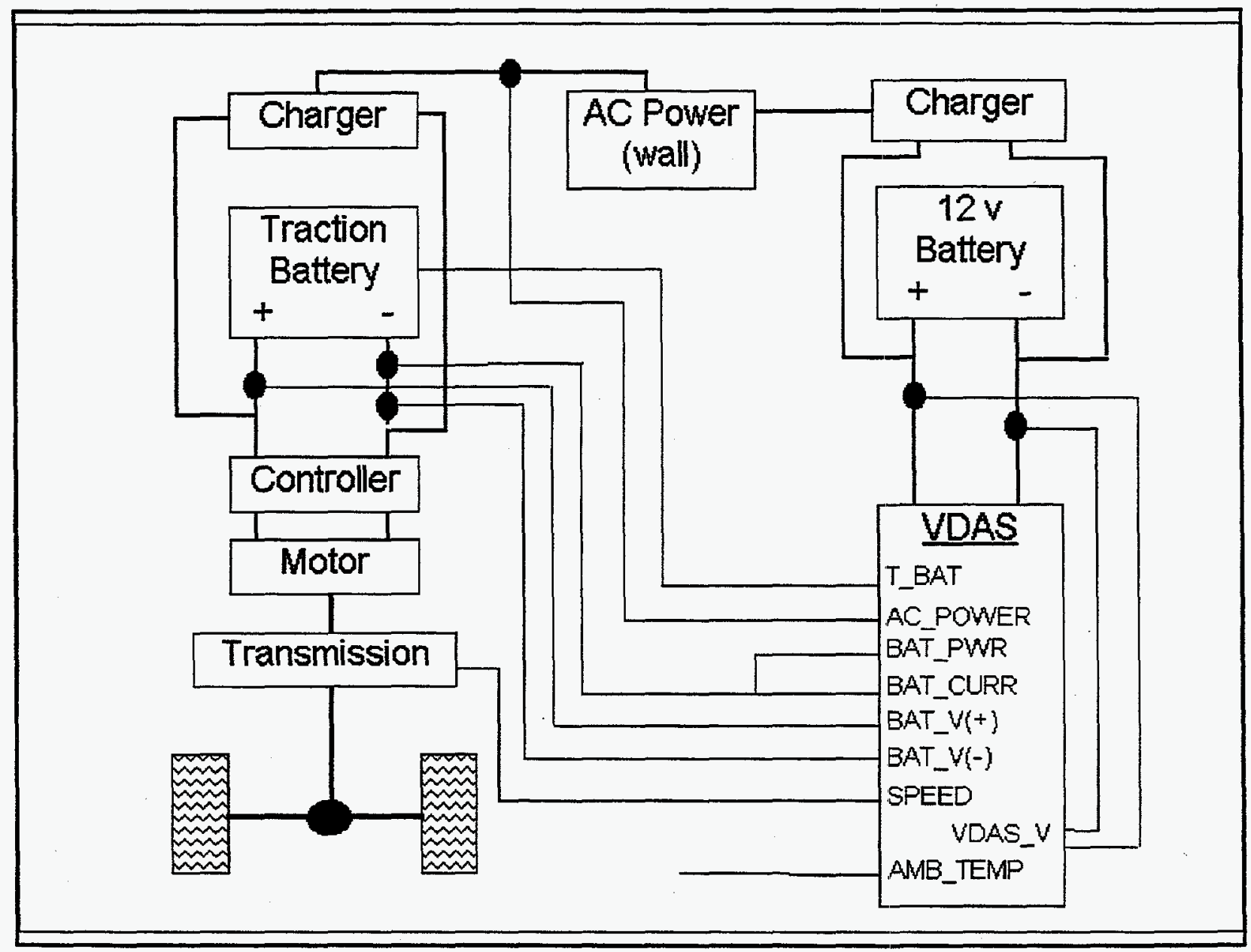

Figure 1. Diagram of Versatile Data Acquisition System (VDAS) instrumentation set-up for the Evcort test vehicle. 
Table 2. Data recorded during testing.

\begin{tabular}{|c|c|c|c|c|}
\hline Parmineter: & Units & Recorded & decorded & \\
\hline ELAP_TIME & $\sec$ & $\mathrm{X}$ & $\mathrm{x}$ & Elapsed Time \\
\hline SPEED & $\mathrm{mph}$ & $\mathrm{x}$ & $\mathrm{X}$ & Vehicle speed from speedometer cable \\
\hline DIGIWORD & & $\mathrm{x}$ & $\mathrm{X}$ & Reserved for VDAS use \\
\hline DISTANCE & miles & $\mathrm{x}$ & & Integrated from SPEED and ELAP_TME \\
\hline BAT_V & volts & $\mathrm{X}$ & $\mathrm{X}$ & Traction battery terminal voltage \\
\hline BAT_CURR & A & $\mathrm{X}$ & $\mathrm{x}$ & $\begin{array}{l}\text { Traction battery current from hall effect device } \\
\text { located at negative battery terminal }\end{array}$ \\
\hline BAT_AH & Ah & $\mathrm{x}$ & $\mathrm{X}$ & $\begin{array}{l}\text { Integrated quantity from BAT_CURR and } \\
\text { ELAP_TIME }\end{array}$ \\
\hline BAT_PWR & $\mathrm{kW}$ & $\mathrm{X}$ & & $\begin{array}{l}\text { Direct measurement from hall effect device } \\
\text { biased by traction battery voltage }\end{array}$ \\
\hline BAT_ENERGY & kWh & $\mathrm{X}$ & & Integrated BAT_PWR \\
\hline T_BAT(F) & ${ }^{\circ} \mathrm{C}$ & $\mathrm{x}$ & $\mathrm{X}$ & $\begin{array}{l}\text { Thermocouple located at center of front traction } \\
\text { battery pack }\end{array}$ \\
\hline T_BAT(R) & ${ }^{\circ} \mathrm{C}$ & $\mathrm{X}$ & $\mathrm{X}$ & $\begin{array}{l}\text { Thermocouple located at center of rear traction } \\
\text { battery pack }\end{array}$ \\
\hline AMB_TEMP & ${ }^{\circ} \mathrm{C}$ & $\mathrm{X}$ & $\mathrm{X}$ & Thermocouple measuring ambient temperature \\
\hline T_MOTOR & ${ }^{\circ} \mathrm{C}$ & $\mathrm{x}$ & $\mathrm{X}$ & $\begin{array}{l}\text { Thermocouple located at surface of traction } \\
\text { motor temperature }\end{array}$ \\
\hline VDAS_V & volts & $\mathrm{x}$ & $\mathrm{X}$ & VDAS input voltage \\
\hline AC_POWER & $\mathrm{kW}$ & & $\mathrm{X}$ & Power input to charger \\
\hline AC_ENERGY & $\mathrm{kWh}$ & & $\mathrm{X}$ & $\begin{array}{l}\text { Energy input to charger integrated from } \\
\text { AC_POWER and ELAP_TIME }\end{array}$ \\
\hline
\end{tabular}




\section{SAE J1634 TEST DESCRIPTION}

SAE J1634 dated May 1993 is organized into 8 sections. The following paragraphs summarize each of these sections. For various reasons, not all of the requirements of SAE J1634 could be strictly adhered to. Deviations from the test procedure which are common to tests performed at all test sites are noted in italics.

\subsection{Purpose and Scope}

The test procedure applies to all-electric vehicles only. Performance of the vehicle is judged on the total vehicle system and is the measured output of the tests described. This test procedure replaces the range and energy consumption section of SAE J227a and is intended to minimize the test-to-test variations inherent in track testing and to set forth a standard industry practice for energy consumption and range testing.

\subsection{Terminology}

Several definitions pertaining to electric vehicle testing are given in this section. The following definitions are of particular importance:

- Battery ampere-hour capacity is based upon a constant -urrent discharge of the battery to a specified minimum cut-off voltage.

- State-of-charge is the residual ampere-hours of a battery after a discharge expressed as a percent of the battery ampere-hour capacity. Note that the state-of-charge is relative to the initial state of the battery and once the battery begins to degrade, $100 \%$ state-ofcharge cannot be attained.

- Start-of-test is defined as the point during a test in which the vehicle key switch is first placed in the "on" position following applicable manufacturer "starting" procedures. 
- End-of-test is defined as the point at which the vehicle has been decelerated to a rest (zero velocity) condition after the appropriate test termination criteria have been met and the key switch is placed in the "off" position.

\subsection{Test Conditions and Instrumentation Common to All Tests}

Prior to the beginning of the tests described, the vehicle shall be stabilized by driving a minimum of $3219 \mathrm{~km}$, but no more than $9978 \mathrm{~km}$, on the Durability Driving Schedule as defined in 40 CFR Part 86, Appendix IV, Section (a) or equivalent.

The test vehicle had in excess of 28,000 accumulated miles $(45,052 \mathrm{~km})$ on the odometer prior to beginning of the tests. The precise method of how this distance was accumulated is unknown. However, the majority of this distance was accumulated in and around Phoenix, AZ. The vehicle was considered well "broken in" by the test participants.

Accessories shall be turned off during the tests. If a vehicle is equipped with air conditioning powered by the same electrical source as the drivetrain, $10 \%$ (up to $1.4 \mathrm{hp}$ ) is to be added to the dynamometer load.

Although the test vehicle was equipped with air conditioning, tests were conducted with the air conditioning turned off and no adjustment in the dynamometer load for this accessory was made.

Regenerative braking is to be enabled during the tests. A methodology is given to account for the braking effect provided by the non-driven wheels when tested on a dynamometer. This methodology essentially requires that the dynamometer used for testing be capable of providing a different load curve for braking than for non-braking situations.

None of the dynamometers used in the test program could be programmed as required by the procedure. Therefore, no adjustments for braking the non-driven wheels were made. 
The inertia weight specified by the procedure is the nearest available inertia weight which equals or exceeds 1.015 times the vehicle test weight (i.e. curb weight plus $136 \mathrm{~kg}$ ).

Tests were conducted at most test locations using two different inertia weights. The EPA advocated that the test inertia weight should be the Equivalent Test Weight as specified in the Code of Federal Regulations, 40 CFR 86, which is used for emissions and certification testing of ICE vehicles. Hence, tests were conducted at inertia weights of $1918 \mathrm{~kg}$ and $1927.5 \mathrm{~kg}$.

The instrumentation used for all measurements must be NIST traceable and be accurate to within $\pm 2 \%$ of full scale, except for distance measurements which must be within $\pm 0.5 \%$.

A fifth-wheel-type device shall be used to measure speed and distance for dynamometer tests unless the dynamometer can measure vehicle speed and integrate distance.

Although this requirement could be met by all test sites by using the measurement provided by their dynamometers, interfacing this data to the VDAS was impractical. All speed and distance (integrated speed) measurements were provided via the vehicle speedometer cable.

\subsection{Data to be Recorded for all Tests}

Section 4.0 provides a listing of data to be recorded for all tests. However, not all test sites provided this information. Those data specific to each test which were obtained from the test sites were supplied to the INEL on computer disks for analysis. Common exceptions to the SAE J1634 requirements are stated below:

- DC watt-hours accumulated separately for regenerative braking and battery discharge. 
Due to limitations in available instrumentation, separate accumulations of $D C$ watthours could not be made. However, this information (accumulated watt-hours for regenerative braking and battery discharge) can be extracted from the data during posttest analysis.

- DC ampere-hours accumulated separately for regenerative braking and battery discharge.

Due to limitations of available instrumentation, separate accumulations of ampere-hours could not be made. However, this information (accumulated ampere-hours for regenerative braking and battery discharge) can be extracted from the data during posttest analysis.

- $\quad \mathrm{AC}$ watt-hours to the charger (i.e. wall plug energy)

- $\quad$ DC watt-hours during recharge (i.e. energy supplied from the charger to the battery)

Due to limitations of available instrumentation, accumulations of $D C$ watt-hours during recharge could not be made. However, this information can be extracted from the data during post-test analysis.

- DC ampere-hours during recharge (i.e. ampere-hours supplied from the charger to the battery)

\subsection{Test Cycles}

The test cycles described by SAE J1634 are those which are familiar to the automobile industry and have been in common use for many years. The UDS cycle is a speed-time profile spanning of 1372 seconds with a distance of approximately 7.5 miles. The average speed on this cycle is $19.6 \mathrm{mph}$ and its maximum speed is $56.7 \mathrm{mph}$. The HWFET speed-time profile is 764 seconds in duration with an approximate distance of 10.2 miles. Its average speed is $48.3 \mathrm{mph}$ with a maximum speed of $59.9 \mathrm{mph}$. The familiar speed tolerances are specified in the 
procedure as $\pm 2 \mathrm{mph}$ within 1 second of the target speed point. The procedure relaxes this speed tolerance for a portion of the UDS cycle provided the vehicle is operated at its maximum available power.

\subsection{Energy Consumption}

The energy consumption test is described as two successive repetitions of the UDS cycle followed by two successive repetitions of the HWFET cycles separated by rest periods of specified durations. This sequence is as follows:

$$
\text { UDS + } 10 \text { minute rest + UDS + HWFET + } 15 \text { seconds rest + HWFET }
$$

The above sequence results in a total test distance of approximately 35.3 miles and has a total test duration of one hour, twenty-one minutes, and twenty-seven seconds (1:21:27)

At the conclusion of the test cycles, the vehicle battery is recharged and the following energy consumption quantities are calculated:

$$
\text { System AC Energy Consumption }=\frac{\mathrm{AC} \text { energyto charger for recharge }}{\text { Distrance Traveled }}
$$

$$
\begin{aligned}
& \text { System DC Energy Consumption }=\frac{\text { DC Energy from charger for recharge }}{\text { Distance Traveled }} \\
& \text { Vehicle DC Energy Consumption }=\frac{\text { DC Energy from battery while driving }}{\text { Distance Traveled }}
\end{aligned}
$$

The latter quantity is to be calculated for the gross DC energy out of the battery as well as the net energy out of the battery (Net energy = total energy out of the battery - energy returned to battery from regenerative braking). 


\subsection{Vehicle Range}

The vehicle range is also determined using the UDS and HWFET driving cycles; however, the specified rest periods differ from those of the Energy Consumption Test. The sequence to be followed is as follows:

$$
\text { UDS + UDS + HWFET }+15 \text { seconds rest }+ \text { HWFET }+10 \text { minute rest }
$$

This sequence is repeated until the test termination (usually based upon the inability of the vehicle to meet some minimum acceleration performance) is reached, at which point the vehicle is to be decelerated rapidly to a stop. The total distance recorded determines the vehicle range.

\subsection{Coastdown Testing}

This section sets forth two methods of determining the dynamometer calibration method. The first method references SAE J1263, "Road Load Measurement and Dynamometer Simulation Using Coastdown Techniques" while the second method describes a frontal area calculation method.

Both methods are weak with respect to producing equivalent results which is critical to producing comparable energy consumption and range results between laboratories. The SAE J1263 method does not apply to electric dynamometers, and will need to be amended to specify the procedure to be used for calibrating this type of test equipment. Therefore, in the case of electric dynamometers, the load versus speed programmed into the dynamometer was that which produced a "best fit" of spee-versus-time curve calculated using SAE J1263. In the case of water brake dynamometers, the SAE J1263 method was used. The frontal area method was not found to accurately estimate the road load of the test vehicle, and therefore was not used. 


\section{COASTDOWN ANALYSIS FOR DYNAMOMETER CALIBRATIONS}

The load curve used for dynamometer calibration to represent the forces on a given dynamometer was derived using the Society of Automotive Engineers Recommended Practice SAE J1263 from coastdown data taken by INEL on this vehicle in 1988. This analysis was used by the test sites to set the road load of each dynamometer. After the onset of the test program, it was noted by Ford personnel that INEL had made an error in determining the vehicle load profile, resulting in a load profile which was $20 \%$ lower than that represented by the vehicle.

For the purposes of this test program, this anomaly is of no consequence, since the objective is to identify variations between laboratories, and not to characterize the EVcort vehicle. Since the erroneous load profile was used by all test sites, the conclusions concerning the variability between test sites presented in this report are still valid. However, the results presented in this report should not be taken as indicative of the performance of this particular vehicle.

Performance test results of this vehicle can be found in "Performance Testing and System Evaluation of the Soleq EVcort Electric Vehicle", DOE/ID-10232, March 1989.

The derived road load force equation use by all test sites is given by:

$$
\mathrm{F}=172.30+0.03195 \mathrm{v}^{2}
$$

where $F$ is in newtons and $v$ is in $\mathrm{km} / \mathrm{h}$.

The data derived from coastdown tests used by each test site for dynamometer calibration is given in Table 3 for each inertia weight. The derived coastdown curve is shown in Figure 2. 
Table 3. Derived coastdown times for each inertia weight.

\begin{tabular}{||l|c|c|}
\hline \multicolumn{1}{|c|}{ Speed Range } & $\begin{array}{c}\text { Derived Coastdown } \\
\text { Time for 1918 kg } \\
\text { Inertia Weight }\end{array}$ & $\begin{array}{c}\text { Derived Coastdown } \\
\text { Time for 1927.5 kg } \\
\text { Inertia Weight }\end{array}$ \\
\hline \hline $60-10 \mathrm{mph}$ & $160.17 \mathrm{sec}$ & $163.36 \mathrm{sec}$ \\
\hline $55-45 \mathrm{mph}$ & $22.68 \mathrm{sec}$ & $23.14 \mathrm{sec}$ \\
\hline $20-10 \mathrm{mph}$ & $44.83 \mathrm{sec}$ & $45.73 \mathrm{sec}$ \\
\hline
\end{tabular}

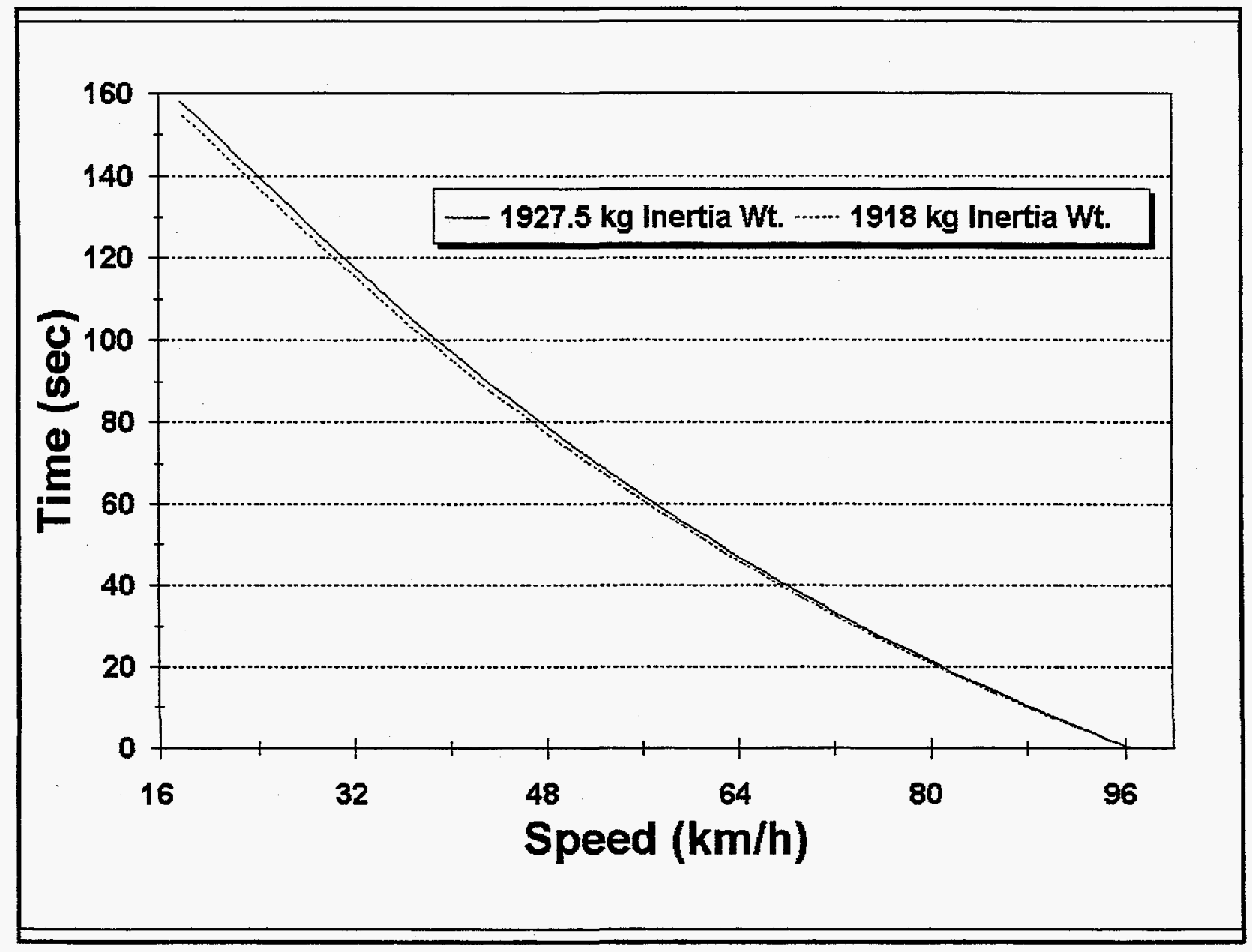

Figure 2. Speed-time coastdown curves used for dynamometer calibrations. 


\section{ROUND-ROBIN TEST VEHICLE PREPARATION AND BATTERY CAPACITY VERIFICATION}

Prior to dynamometer laboratory testing, constant-current discharges were performed on the vehicle battery pack in the INEL Battery Laboratory to "break-in" the battery pack and to ascertain the pack's condition. Results of these 3-hour-rate constant-current discharges are given below.

One issue in executing the test procedure at other laboratories was how to determine the condition of the battery pack. It was hypothesized that the vehicle could be driven on the chassis dynamometer at a 3-hour-rate constant-current to determine the pack capacity. This hypothesis was confirmed by comparing the battery laboratory test results with those results on the dynamometer. It was concluded that, for this vehicle, an accurate measure of the battery ampere-hour capacity could be made by using the vehicle/dynamometer as a load band for discharging the battery. This finding was crucial in being able to verify the battery capacity at test sites which do not have access to battery test equipment. 



\section{DATA ACQUISITION SYSTEM COMPARISON}

Use of the INEL Versatile Data Acquisition System raised some questions regarding its precision and accuracy. A study was performed while testing in the INEL Hybrid/Electric Vehicle Laboratory that compared measurements taken with the Laboratory Data Acquisition System (LDAS) and the Versatile Data Acquisition System (VDAS) which was planned to be used at the various test sites. Data from the 1/17/94 test of the Soleq EVcort was compared. Figures 3 through 5 show the measured battery voltage, current, and vehicle speed for a portion of the UDS segment of the driving cycle test performed with each data acquisition system.

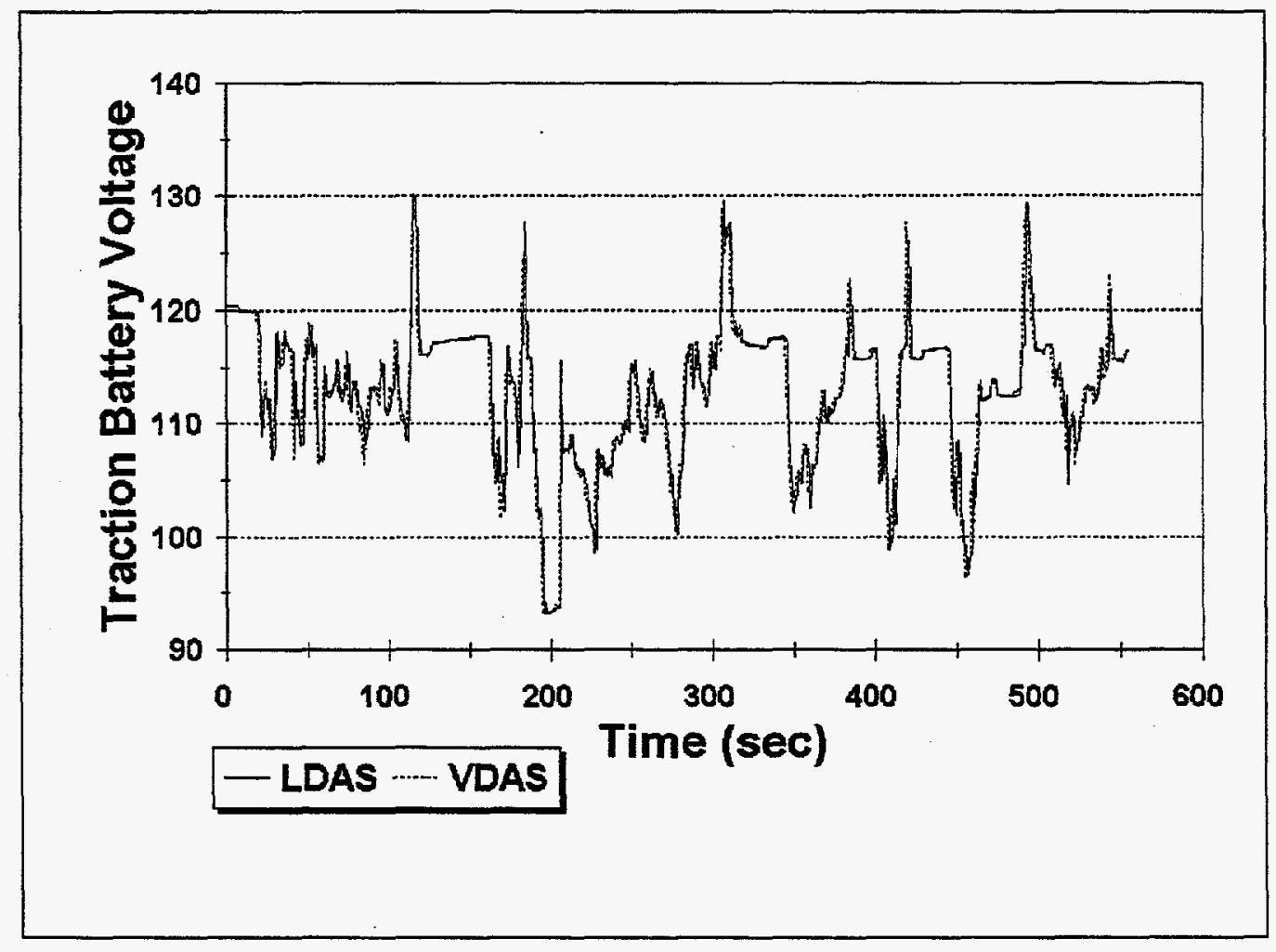

Figure 3. Comparison of traction battery voltage measured using two different data acquisition systems. 


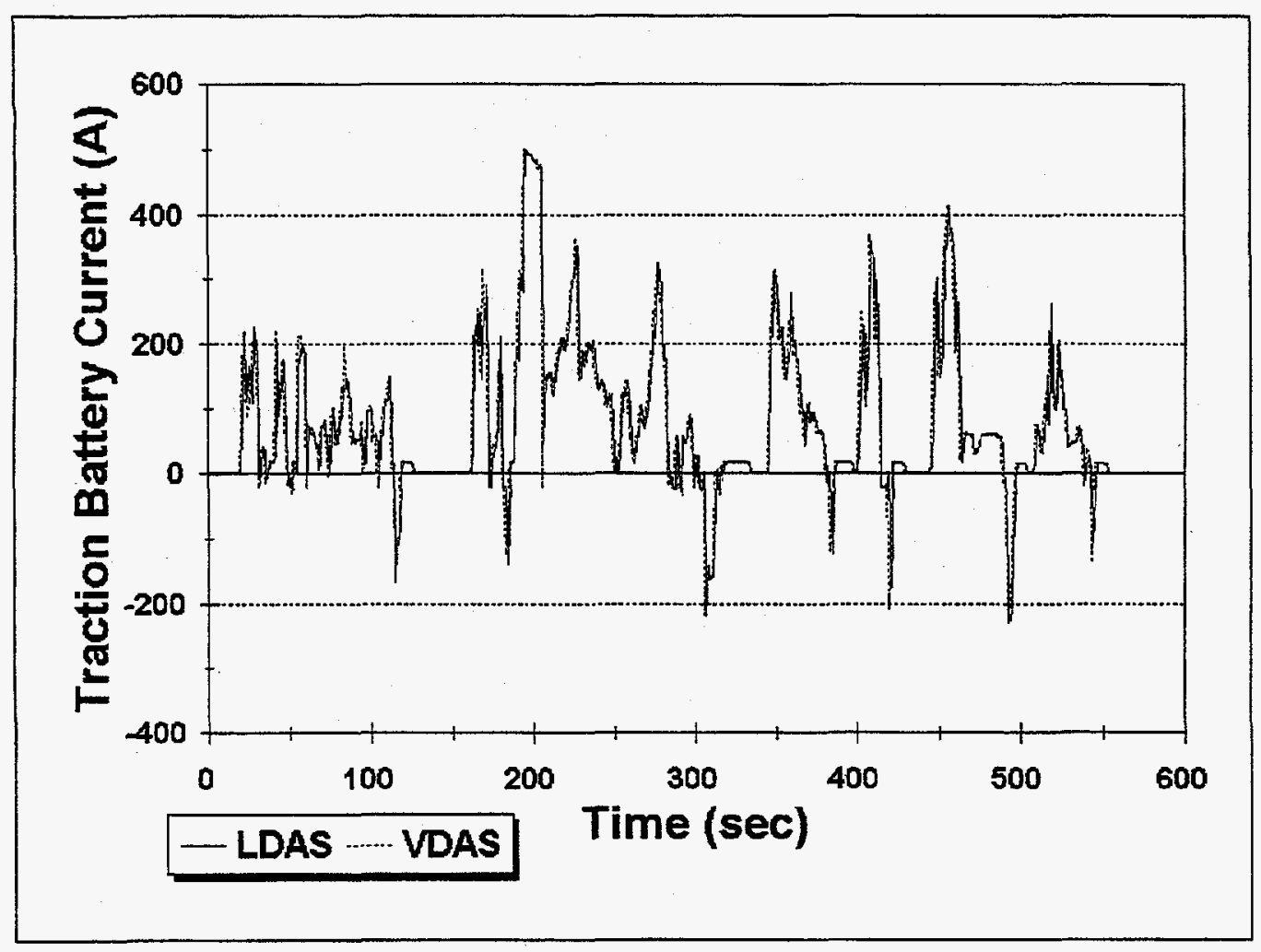

Figure 4. Comparison of traction battery current measured using two different data acquisition systems.

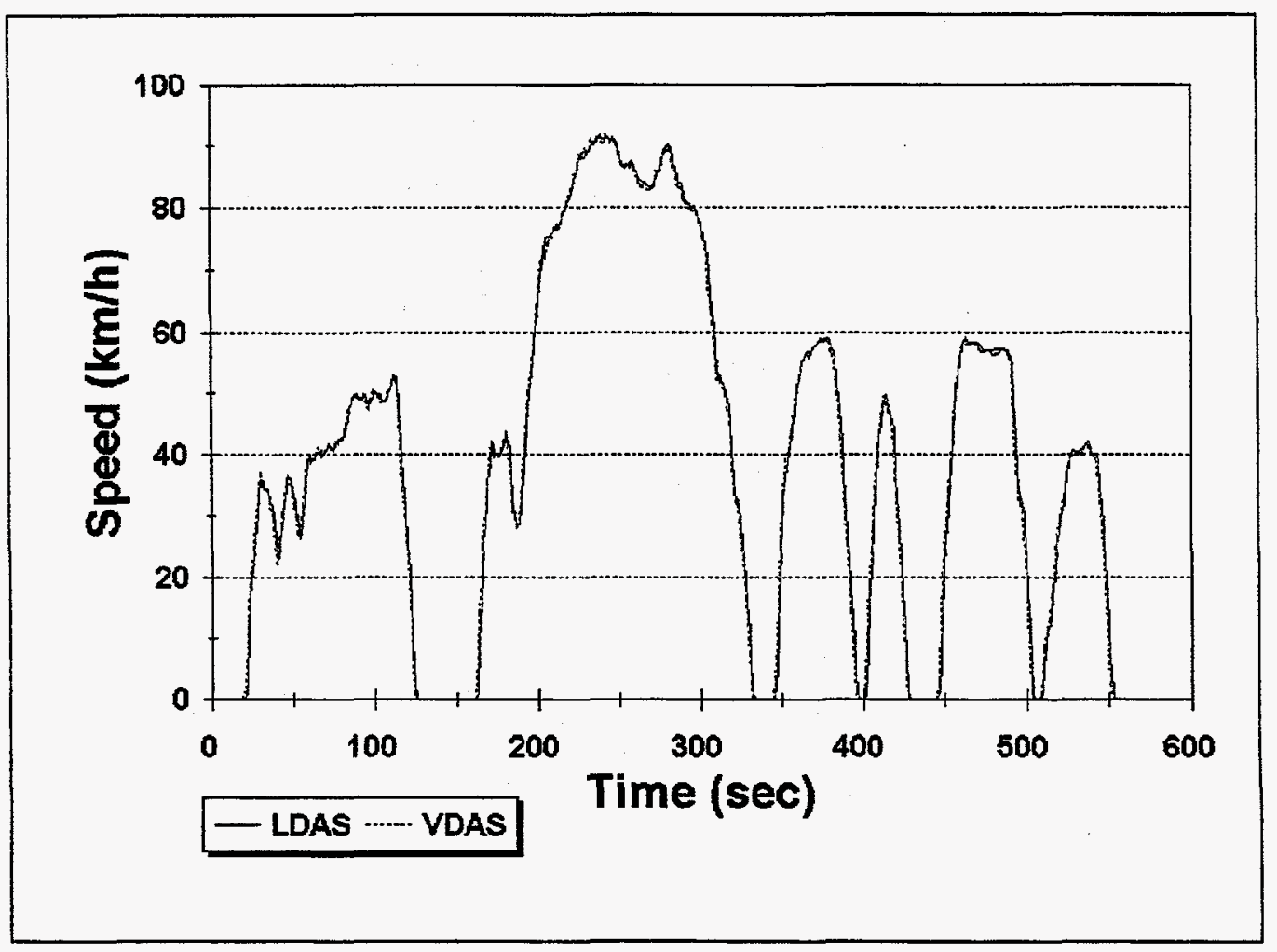

Figure 5. Comparison of vehicle speed measured using two different data acquisition systems. 
It is noted that these two instrumentation systems operate independently, and therefore the timing of the data cannot be aligned exactly. However, by matching the points in each data set in which the first instance of vehicle speed occurs, one can be reasonable assured that these data sets are coincident within \pm 1 second.

Both systems sample data at $100 \mathrm{~ms}$ intervals and write the data at 1-second intervals. However, the LDAS writes the measured values for speed, voltage, current at each second, while the VDAS averages the $100 \mathrm{~ms}$ data and writes this average each second. For the LDAS, parameters (such as energy, distance, and ampere-hours) are integrated using all sampled data, with the result written each second.

The LDAS data set had a greater number of significant digits for the measured parameters than the VDAS.

As the plots show, agreement between the two data systems is good, especially taking into consideration the above described differences.

A comparison was made on the integrated parameters of interest for the entire furst UDS cycle. Table 4 summarizes the results of this comparison.

Table 4. Comparison of measurements made with INEL's Laboratory Data Acquisition System (LDAS) and the Versatile Data Acquisition System (VDAS).

\begin{tabular}{||l|c|c|c|}
\hline \multicolumn{1}{|c|}{ Parameter } & LDAS Result & VDAS Result & $\begin{array}{c}\text { Percent } \\
\text { difference }\end{array}$ \\
\hline \hline Net Ampere-hours & 24.130 & 23.806 & $1.3 \%$ \\
\hline Net Energy (kWh) & 2.454 & 2.428 & $1.1 \%$ \\
\hline Distance (km) & 12.003 & 11.92 & $0.7 \%$ \\
\hline $\begin{array}{l}\text { Net Energy } \\
\text { Consumption } \\
(W h / k m)\end{array}$ & 204 & 204 & $0.0 \%$ \\
\hline
\end{tabular}


For the purposes of this comparison, all values were integrated from the 1-second data contained in the data files, as opposed to using the integrated values produced by the LDAS. It is noted that the LDAS data fields contained more significant digits than the VDAS data fields, which may account for some of the differences in the results. 


\section{TEST RESULTS}

The results of the tests performed at the individual test sites are presented in this section of this report. Comparisons of these results are presented in the following section. All data analyses presented in this section were performed independently by the INEL from the data recorded at each test site. (A summary of these data files archived at the INEL is given in Table 5 "Vehicle Test Data Summary Sheet". For this reason, there may be small differences between these data and the data contained in the individual site reports contained in the appendices.

\section{Idaho National Engineering Laboratory Tests}

Six tests were performed in the INEL Hybrid/Electric Vehicle Test Laboratory: two constant-current discharges, two energy consumption tests, and two range tests. The energy consumption and range tests were performed at each of two test weights (1918 and $1927.5 \mathrm{~kg}$ ) corresponding to curb weight plus $136 \mathrm{~kg}$ and the equivalent test weight (as requested by the EPA).

Dynamometer settings were determined by repetitively coasting the vehicle from approximately $100 \mathrm{~km} / \mathrm{h}$ to $16 \mathrm{~km} / \mathrm{h}$ and adjusting the dynamometer load coefficients such that good agreement between the target coastdown curve and the curve calculated via SAE J1263 was attained.

Results in the form specified by SAE J1634 of the driving cycle and constant current dynamometer tests are shown in Table 6. 
, 
Table 5. Vehicle test data summary sheet.

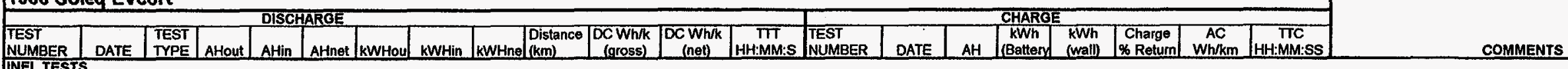

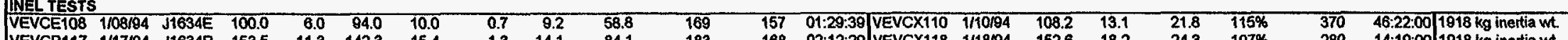

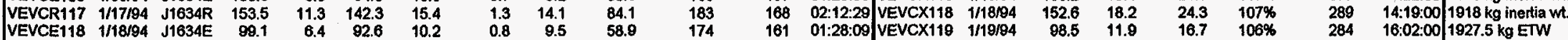

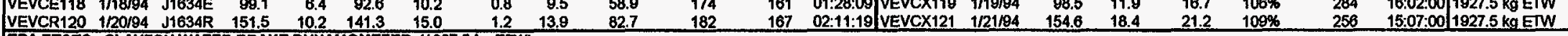

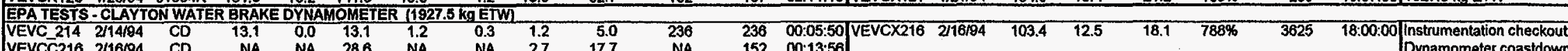

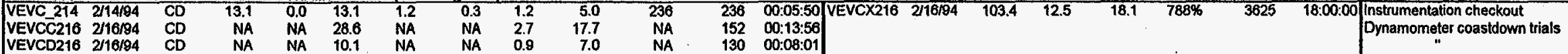
VEVCT216 2/16194 CD NA NA 13.4 NA NA 12 10.1

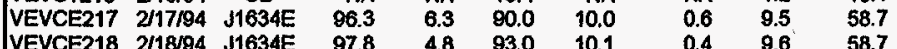

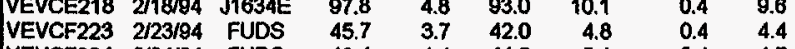
$\begin{array}{llllllllll}\text { VEVCF224 } & 2 / 24 / 94 & \text { FUDS } & 48.4 & 4.4 & 44.0 & 5.1 & 0.4 & 4.7 & 24.7\end{array}$

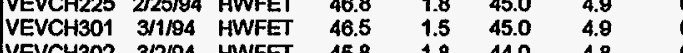

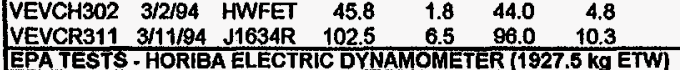
\begin{tabular}{lllllll}
\hline VEVCE429 & $4 / 29194$ & $11634 \mathrm{C}$ & 103.1 & 7.1 & 96.0 & 10.1 \\
VEVCE502 & $52 / 294$ & $\mathrm{J1634E}$ & 102.4 & 7.3 & 95.0 & 10.0
\end{tabular} VEVCF505 $5 / 5 / 94$ FUDS 50.3 $\begin{array}{rrrr}\text { VEVCH5O9 } & 5 / 9194 & \text { HWFET } & 54.1 \\ \text { VEVCR510 } & 5 / 10194 & \text { J1634R } & 1097\end{array}$ $\begin{array}{lrrr}\text { VEVCR2510 } & 5 / 10 / 94 & \mathrm{J1634R} & 109.7 \\ \text { VEVCE525 } & 5 / 25 / 94 & \mathrm{J1634E} & 97.3\end{array}$ $\begin{array}{rrrr}\text { VEVCE525 } & 5 / 25 / 94 & \mathrm{~J} 1634 \mathrm{R} & 97.3 \\ \text { VEVCE526 } & 5 / 26 / 94 & \mathrm{~J} 1634 \mathrm{E} & 104.8\end{array}$

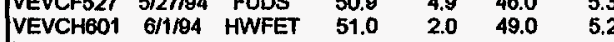
VEVCR602 $6 / 2194 \quad J 1634 R \quad 109.9$ \begin{tabular}{l}
$N$ \\
\multirow{N}{*}{}
\end{tabular}

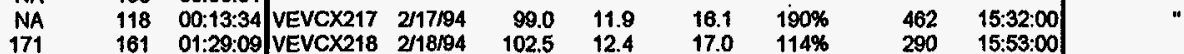

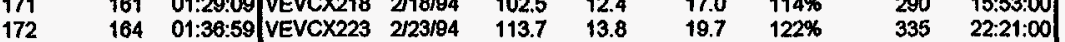

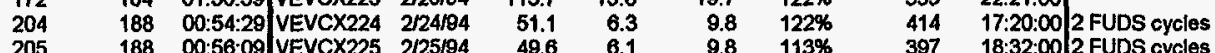
$232 \times 18200.60 .09$ VEVCX25 225194

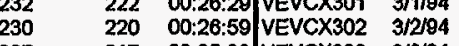
\begin{tabular}{llll}
217 & $00: 35: 29$ & VEVCX 303 & $3 / 3 / 94$ \\
\hline
\end{tabular}

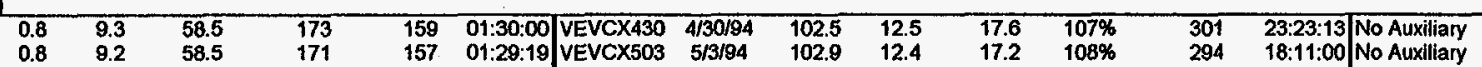

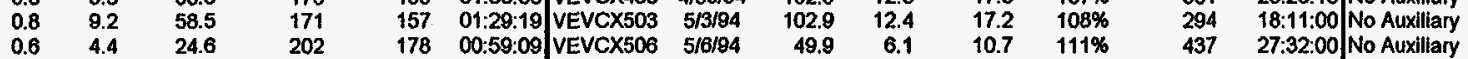

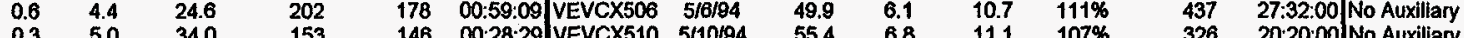

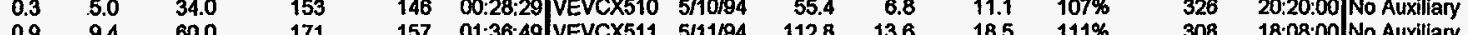

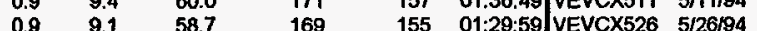

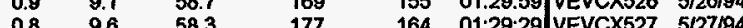

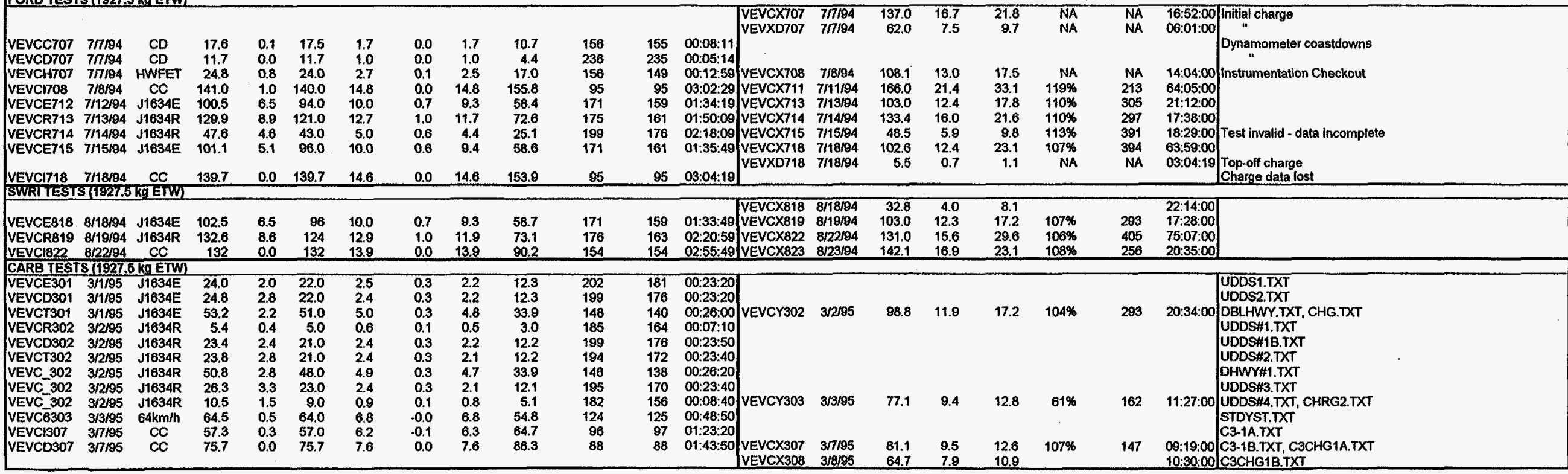


Table 5. (Continued

Column Headings - Discharge

\begin{tabular}{|c|c|}
\hline TEST NUM: & Name of data file archived at INE \\
\hline & Date testldata file was ended \\
\hline TEST TYPE & $\begin{array}{l}\text { J1634E- SAE J1634 Energy Consumption Test } \\
\text { J1634R - SAE J1634 Range Test } \\
\text { CD - Vehicle costdown trials } \\
\text { FUDS. Federal Urban Driving Schedule } \\
\text { HWFET - Highway Fuel Economy Test driving schedule } \\
\text { CC. Constant curront discharge } \\
64 \mathrm{~km} / \mathrm{h} \text { - Constant speed lest @ } 64 \mathrm{~km} / \mathrm{h}\end{array}$ \\
\hline AHout & Total ampere-hours removed from traction battery \\
\hline AHin & Total ampere-hours seturned to traction battery (regen) \\
\hline AHnet & Net traction baltery ampere-hours (AHout-AHin) \\
\hline KWHout & Total energy removed from traction battery \\
\hline KWWHin & Tolal energy retumed to (raction battery (regen) \\
\hline KWHnet & Net traction battery energy (KWHout-KWHin) \\
\hline Distance & Distance traveled during test \\
\hline DCWh/km (gross) & (KWHout/Distance) 1000 \\
\hline DCWh/km (net) & $($ KWHneUDistance) 1000 \\
\hline$\pi \pi$ & Total time of test \\
\hline
\end{tabular}

Column Headings - Charge

\begin{tabular}{|c|c|}
\hline EST NUME & Name of data fi \\
\hline & Date lestuata fille was ended \\
\hline & d to traction baltery during charge \\
\hline kWh (battery) & Total energy returned to fraction battery \\
\hline kWh (wall) & Total AC energy delivered to charger \\
\hline Charge \% Return & T(AH/AHnet) 100 \\
\hline AC Whikm & $($ KWh (wall)/Distance) 1000 \\
\hline$\pi$ & Total time of charge \\
\hline
\end{tabular}


Table 6. Results of tests conducted on the INEL Clayton electric dynamometer.

\begin{tabular}{||l|c|c|c|c|c|c||}
\hline \multicolumn{1}{|c|}{ Test } & $\begin{array}{c}\text { Ampere- } \\
\text { hours }\end{array}$ & $\begin{array}{c}\text { System AC } \\
\text { Energy } \\
\text { Consumption } \\
(\mathbf{W h} / \mathbf{k m})\end{array}$ & $\begin{array}{c}\text { System DC } \\
\text { Energy } \\
\text { Consumption } \\
(\mathbf{W h} / \mathbf{k m})\end{array}$ & $\begin{array}{c}\text { Gross Vehicle } \\
\text { DC Energy } \\
\text { Consumption } \\
(\mathbf{W h} / \mathbf{k m})\end{array}$ & $\begin{array}{c}\text { Net Vehicle } \\
\text { DC Energy } \\
\text { Consumption } \\
\text { (Wh/km) }\end{array}$ & $\begin{array}{c}\text { Range } \\
\text { (km) }\end{array}$ \\
\hline \hline $\begin{array}{l}\text { Energy } \\
\text { Consumption } \\
(1918 \mathrm{~kg})\end{array}$ & - & 286 & 214 & 169 & 157 & - \\
\hline $\begin{array}{l}\text { Range } \\
(1918 \mathrm{~kg})\end{array}$ & - & 289 & 216 & 183 & 168 & 84.1 \\
\hline $\begin{array}{l}\text { Energy } \\
\text { Consumption } \\
(1927.5 \mathrm{~kg})\end{array}$ & - & 282 & 214 & 169 & 157 & - \\
\hline $\begin{array}{l}\text { Range } \\
(1927.5 \mathrm{~kg})\end{array}$ & - & 279 & 223 & 182 & 167 & 82.7 \\
\hline
\end{tabular}

\section{Environmental Protection Agency Tests}

Tests at the EPA located in Ann Arbor, MI were conducted on each of two dynamometers: a Clayton hydrokinetic dynamometer and a Horiba electric dynamometer. The Clayton dynamometer is a twin roll type while the Horiba is a large single roll type. Each of these dynamometers were calibrated using EPA's standard procedures. In the case of the Clayton dynamometer, coastdowns were performed and the power absorption setting adjusted until the speed-time for the coastdown was the best match to the target speed-time as could be obtained. The Horiba dynamometer is calibrated by inputting the target coastdown times into the dynamometer controller. The dynamometer then repetitively and automatically performs vehicle coastdowns, automatically adjusting the dynamometer load calibration until the coastdown times match the target coastdown times. This process typically required 4 to 5 coastdown trials. 
Eight tests (not including coastdown trials) were conducted on EPA's Clayton Dynamometer. Three of these tests followed the SAE J1634 driving profile and art pertinent to this study. These tests were performed using an inertia weight of $1927.5 \mathrm{~kg}$ (the equivalent test weight specified for internal combustion vehicles by the Code of Federal Regulations. The other tests (repetitive HWFET and UDS cycles) were performed for EPA's own interest. Appendix _ contains an accounting of the results of these tests. Results of the SAE J1634 tests performed by EPA on their Clayton dynamometer are given in Table 7.

Table 7. Results of tests conducted on EPA's Clayton Dynamometer.

\begin{tabular}{||l|c|c|c|c|c|c||}
\hline \multicolumn{1}{|c|}{ Test } & $\begin{array}{c}\text { Ampere- } \\
\text { hours }\end{array}$ & $\begin{array}{c}\text { System AC } \\
\text { Energy } \\
\text { Consumption } \\
\text { (Wh/km) }\end{array}$ & $\begin{array}{c}\text { System DC } \\
\text { Energy } \\
\text { Consumption } \\
\text { (Wh/km) }\end{array}$ & $\begin{array}{c}\text { Gross Vehicle } \\
\text { DC Energy } \\
\text { Consumption } \\
\text { (Wh/km) }\end{array}$ & $\begin{array}{c}\text { Net Vehicle } \\
\text { DC Energy } \\
\text { Consumption } \\
\text { (Wh/km) }\end{array}$ & $\begin{array}{c}\text { Range } \\
\text { (km) }\end{array}$ \\
\hline \hline $\begin{array}{l}\text { Energy } \\
\text { Consumption } \\
(1927.5 \mathrm{~kg})\end{array}$ & - & 282 & 211 & 171 & 161 & \\
\hline $\begin{array}{l}\text { Energy } \\
\text { Consumption } \\
(1927.5 \mathrm{~kg})\end{array}$ & - & 317 & 235 & 172 & 164 & \\
\hline $\begin{array}{l}\text { Range } \\
(1927.5 \mathrm{~kg})\end{array}$ & - & $\mathrm{NA}$ & $\mathrm{NA}$ & 170 & 159 & 60.8 \\
\hline
\end{tabular}

Thirteen tests (not including coastdown trials) were conducted on EPA's Horiba dynamometer. Four of these tests (three energy consumption and one range test) followed the SAE J1634 driving profile with the prescribed vehicle conditions (i.e. accessories off) and are pertinent to this study. These tests were performed using an inertia weight of $1927.5 \mathrm{~kg}$ (the equivalent test weight specified for internal combustion vehicles by the Code of Federal Regulations. The other tests (SAE J1634 range and energy consumption, and repetitive HWFET and UDS cycles) were performed for EPA's own interest with varying numbers electrical 
accessories turned on. Appendix $B$ contains an accounting of the results of these tests. Results of the SAE J1634 tests performed by EPA on their Horiba dynamometer are given in Table 8.

Table 8. Results of tests conducted on EPA's Horiba dynamometer.

\begin{tabular}{|c|c|c|c|c|c|c|}
\hline Test & $\begin{array}{c}\text { Ampere- } \\
\text { hours }\end{array}$ & $\begin{array}{c}\text { System AC } \\
\text { Energy } \\
\text { Consumption } \\
\text { (Wh/km) }\end{array}$ & $\begin{array}{c}\text { System DC } \\
\text { Energy } \\
\text { Consumption } \\
(\mathbf{W h} / \mathbf{k m})\end{array}$ & $\begin{array}{l}\text { Gross Vehicle } \\
\text { DC Energy } \\
\text { Consumption } \\
(\mathbf{W h} / \mathbf{k m})\end{array}$ & $\begin{array}{c}\text { Net Vehicle } \\
\text { DC Energy } \\
\text { Consumption } \\
\text { (Wh/km) }\end{array}$ & $\begin{array}{c}\text { Range } \\
(\mathbf{k m})\end{array}$ \\
\hline $\begin{array}{c}\text { Energy } \\
\text { Consumption } \\
(1927.5 \mathrm{~kg})\end{array}$ & - & 282 & 209 & 173 & 159 & \\
\hline $\begin{array}{c}\text { Energy } \\
\text { Consumption } \\
(1927.5 \mathrm{~kg})\end{array}$ & - & 281 & 210 & 170 & 157 & \\
\hline $\begin{array}{c}\text { Energy } \\
\text { Consumption } \\
(1927.5 \mathrm{~kg})\end{array}$ & & 263 & 202 & 169 & 155 & \\
\hline $\begin{array}{c}\text { Range } \\
(1927.5 \mathrm{~kg})\end{array}$ & - & 295 & 225 & 171 & 157 & 60.0 \\
\hline
\end{tabular}

\section{Ford Motor Company Tests}

Five tests pertinent to this study were conducted by Ford Motor Company in Dearborn, MI on a Clayton hydrokinetic dynamometer. These tests were performed using an inertia weight of $1927.5 \mathrm{~kg}$ (the equivalent test weight specified for internal combustion vehicles by the Code of Federal Regulations. Two constant-current discharges were conducted to verify the battery capacity (one each before and after the driving cycle tests). Ford also performed two energy economy tests and one range test. Appendix B contains an accounting of the results of these tests. Results of the SAE J1634 tests performed by Ford on their Clayton dynamometer are given in Table 9. 
Table 9. Results of tests conducted on Ford's Clayton dynamometer.

\begin{tabular}{|c|c|c|c|c|c|c|}
\hline Test & $\begin{array}{c}\text { Ampere- } \\
\text { hours }\end{array}$ & $\begin{array}{c}\text { System AC } \\
\text { Energy } \\
\text { Consumption } \\
(\mathbf{W h} / \mathbf{k m}) \\
\end{array}$ & $\begin{array}{c}\text { System DC } \\
\text { Energy } \\
\text { Consumption } \\
(W h / k m)\end{array}$ & $\begin{array}{c}\text { Gross Vehicle } \\
\text { DC Energy } \\
\text { Consumption } \\
(\mathbf{W h} / \mathbf{k m})\end{array}$ & $\begin{array}{c}\text { Net Vehicle } \\
\text { DC Energy } \\
\text { Consumption } \\
(\mathbf{W h} / \mathbf{k m})\end{array}$ & $\begin{array}{c}\text { Range } \\
(\mathbf{k m})\end{array}$ \\
\hline $\begin{array}{l}\text { Constant } \\
\text { Current }\end{array}$ & 141 & - & - & - & - & - \\
\hline $\begin{array}{l}\text { Energy } \\
\text { Consumption } \\
(1927.5 \mathrm{~kg})\end{array}$ & - & 288 & 216 & 171 & 159 & \\
\hline $\begin{array}{l}\text { Energy } \\
\text { Consumption } \\
(1927.5 \mathrm{~kg})\end{array}$ & - & 291 & 219 & 171 & 161 & \\
\hline $\begin{array}{l}\text { Range } \\
(1927.5 \mathrm{~kg})\end{array}$ & - & 297 & 220 & 175 & 161 & 72.6 \\
\hline $\begin{array}{l}\text { Constant } \\
\text { Current }\end{array}$ & 140 & - & - & - & - & - \\
\hline
\end{tabular}

\section{Southwest Research Institute Tests}

Three tests were performed at the Southwest Research Institute in San Antonio, TX: an energy economy test, a range test and a constant current discharge to verify battery capacity. These tests were performed using an inertia weight of $1927.5 \mathrm{~kg}$ (the equivalent test weight specified for internal combustion vehicles by the Code of Federal Regulations. SwRI also compared the results of the on-board VDAS to their own instrumentation system with good correlation. A full report of these tests and observations made by SwRI is contained in Appendix C. Results of the SAE J1634 tests performed by SwRI on their Clayton hydrokinetic dynamometer are given in Table 10. 
Table 10. Results of tests conducted on Southwest Research Institute's Clayton dynamometer.

\begin{tabular}{||l|c|c|c|c|c|c||}
\hline \multicolumn{1}{|c|}{ Test } & $\begin{array}{c}\text { Ampere- } \\
\text { hours }\end{array}$ & $\begin{array}{c}\text { System AC } \\
\text { Energy } \\
\text { Consumption } \\
(\mathbf{W h} / \mathbf{k m})\end{array}$ & $\begin{array}{c}\text { System DC } \\
\text { Energy } \\
\text { Consumption } \\
(\mathbf{W h} / \mathbf{k m})\end{array}$ & $\begin{array}{c}\text { Gross Vehicle } \\
\text { DC Energy } \\
\text { Consumption } \\
(\mathbf{W h} / \mathbf{k m})\end{array}$ & $\begin{array}{c}\text { Net Vehicle } \\
\text { DC Energy } \\
\text { Consumption } \\
\text { (Wh/km) }\end{array}$ & $\begin{array}{c}\text { Range } \\
(\mathbf{k m})\end{array}$ \\
\hline \hline $\begin{array}{l}\text { Energy } \\
\text { Consumption } \\
(1927.5 \mathrm{~kg})\end{array}$ & - & 283 & 212 & 171 & 159 & \\
\hline $\begin{array}{l}\text { Range } \\
(1927.5 \mathrm{~kg})\end{array}$ & - & 282 & 214 & 176 & 163 & 73.1 \\
\hline $\begin{array}{l}\text { Constant } \\
\text { Current }\end{array}$ & 132 & - & - & - & & - \\
\hline
\end{tabular}

\section{California Air Resources Board Tests}

Three tests pertinent to this study were performed at the California Air Resources Board (CARB) located in Rosemead, CA: an energy economy test, a range test and a constant current discharge test to verify battery capacity. These tests were performed using an inertia weight of $1927.5 \mathrm{~kg}$ (the equivalent test weight specified for internal combustion vehicles by the Code of Federal Regulations). The data presented below were extracted from the VDAS data files of the tests conducted were provided to the INEL at the conclusion of CARB's testing activities.

Results of the SAE J1634 tests performed by CARB on their Clayton hydrokinetic dynamometer are given in Table 11.

The recharge data file supplied by CARB indicated that the ampere-hour charge return after the J1634 range test was only $61 \%$ of the ampere-hours removed. Thus it is judged that the data available does not reflect a complete recharge and reasonable values for the system $\mathrm{AC}$ and system DC energy consumption. 
Table 11. Results of tests conducted on CARB's Clayton dynamometer.

\begin{tabular}{||l|c|c|c|c|c|c||}
\hline \hline \multicolumn{1}{|c|}{ Test } & $\begin{array}{c}\text { Ampere- } \\
\text { hours }\end{array}$ & $\begin{array}{c}\text { System AC } \\
\text { Energy } \\
\text { Consumption } \\
(\mathbf{W h} / \mathbf{k m})\end{array}$ & $\begin{array}{c}\text { System DC } \\
\text { Energy } \\
\text { Consumption } \\
(\mathbf{W h} / \mathbf{k m})\end{array}$ & $\begin{array}{c}\text { Gross Vehicle } \\
\text { DC Energy } \\
\text { Consumption } \\
(\text { Wh/km) }\end{array}$ & $\begin{array}{c}\text { Net Vehicle } \\
\text { DC Energy } \\
\text { Consumption } \\
(\mathbf{W h} / \mathbf{k m})\end{array}$ & $\begin{array}{c}\text { Range } \\
(\mathbf{k m})\end{array}$ \\
\hline \hline $\begin{array}{l}\text { Energy } \\
\text { Consumption } \\
(1927.5 \mathrm{~kg})\end{array}$ & - & 281 & 206 & 170 & 156 & - \\
\hline $\begin{array}{l}\text { Range } \\
(1927.5 \mathrm{~kg})\end{array}$ & - & N/A & N/A & 173 & 158 & 73.1 \\
\hline $\begin{array}{l}\text { Constant } \\
\text { Current }\end{array}$ & 133 & - & - & - & & - \\
\hline
\end{tabular}




\section{CONCLUSIONS}

As a result of this round-robin test program, the following observations and conclusions can be made.

The net vehicle DC energy consumption and the gross system DC energy consumption determined from the data across all test sites are in good agreement. However, the agreement in the system DC energy consumption and the system AC energy consumption measurements do not agree within acceptable limits. Figure 6 shows this phenomenon for the SAE J1634 energy economy tests performed at each test site. This phenomenon is attributed to variations in the battery charging behavior. It can be observed from Table 12 that although the charger efficiency remained nearly the same at all test sites, the observed battery efficiency varied significantly. Battery efficiency is calculated as the quotient of the net energy measured on the driving cycle, and the energy used to recharge the battery. 
. 


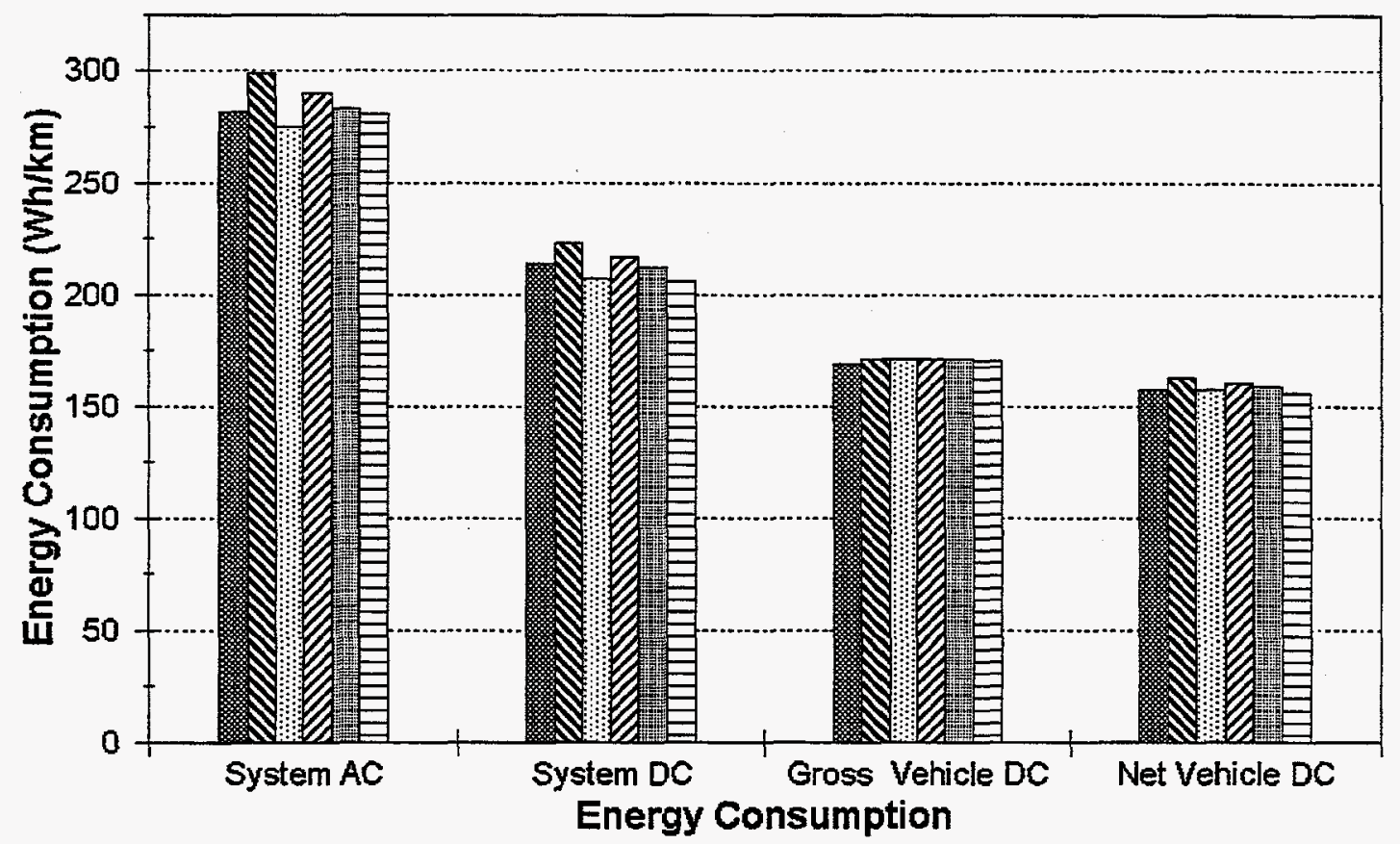

INEL-Clayton Electric Dyno

EPA-Horiba Electric Dyno

MPA-Clayton Hydrokinetic Dyno

SWRI - Clayton Hydrokinetic Dyno

Ford-Clayton Hydrokinetic Dyno

CARB - Clayton Hydrokinetic Dyno

Figure 6. Comparison of energy consumption measured at each test site.

Table 12. System energy economy and overall charger efficiency for SAE J1634 energy economy tests (1927.5 inertia weight) at all test sites.

\begin{tabular}{|l|c|c|c|c|}
\hline Test Site & $\begin{array}{l}\text { System AC Energy } \\
\text { Consumption (Wh/km) }\end{array}$ & $\begin{array}{l}\text { System DC Energy } \\
\text { Consumption(Wh/km) }\end{array}$ & $\begin{array}{l}\text { Overall } \\
\text { Charger } \\
\text { Efficiency (\%) }\end{array}$ & $\begin{array}{c}\text { Battery } \\
\text { Recharge } \\
\text { Efficiency (\%) }\end{array}$ \\
\hline INEL & 282 & 214 & 76 & 79 \\
\hline $\begin{array}{l}\text { EPA (Clayton } \\
\text { Dynamometer) }\end{array}$ & 299 & 223 & 74 & 77 \\
\hline $\begin{array}{l}\text { EPA (Horiba } \\
\text { Dynamometer) }\end{array}$ & 275 & 207 & 75 & 82 \\
\hline Ford & 290 & 217 & 75 & 79 \\
\hline SwRI & 283 & 212 & 75 & 81 \\
\hline CARB & 281 & 206 & 73 & 82 \\
\hline
\end{tabular}


Vehicle range, as determined by the test procedure and each laboratory, varied significantly as shown in Figure 7. This variation is believed to be due to inadequacies in determining when the test termination criterion is reached during the test and ambiguities in the wording of this item in the test procedure itself. Additionally, the driving profile is such that the most severe accelerations occur only once per cycle. Therefore, if it is determined that the vehicle can meet the cycle within the speed tolerance, several additional kilometers are driven before high power demands are again required, thus leading to large discrepancies in vehicle range determination.

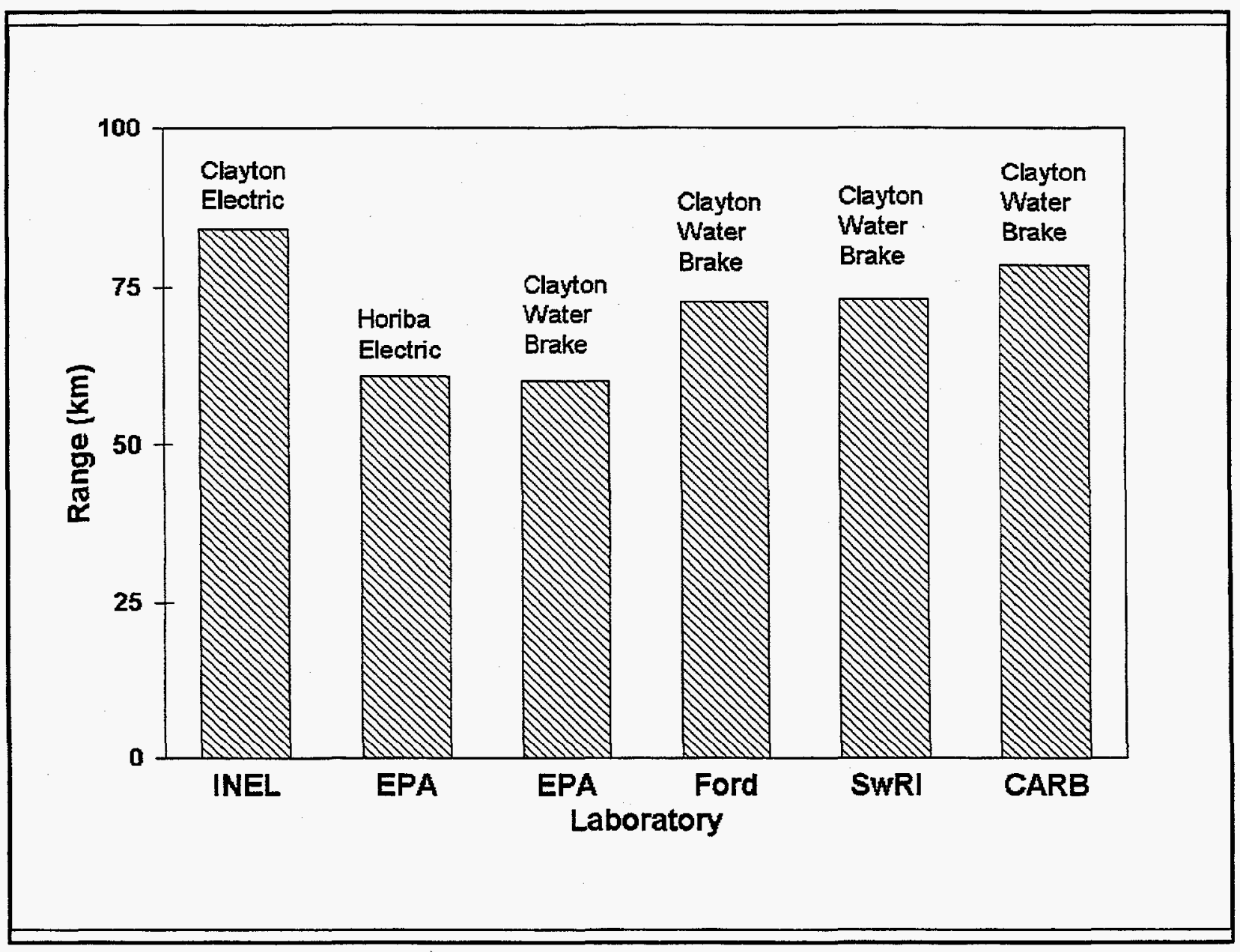

Figure 7. Comparison of vehicle range measured at each test site. 


\section{ADDITIONAL OBSERVATIONS MADE DURING TESTING}

The Sonnenschein DF6V160 batteries have exhibited a high infant mortality rate, which was unexpected based upon previous INEL experience with these batteries. Out of 30 modules, 11 failed prematurely. While it has been concluded that the battery behavior had an effect on test results, the magnitude of this effect cannot be ascertained from the data collected during this test program. Battery condition was monitored throughout the test program, and all tests were performed with the traction battery within the procedure's acceptable capacity limits.

The VDAS performed well. The EVcort tests permitted comparisons of the VDAS, LDAS, and SwRI's instrumentation, and all data acquisition systems were in good agreement.

Comparison of battery laboratory $\mathrm{C} / 3$ rate discharges and discharging the battery with the vehicle on the dynamometer at a constant current equivalent to the $\mathrm{C} / 3$ rate $(46 \mathrm{~A} \pm 1 \mathrm{~A})$ was found to be an acceptable method of measuring battery capacity.

Acceptable departures from the driving profile prescribed by SAE J1634 are not well defined. This deficiency in the procedure is even more noticeable due to the EVcort's marginal acceleration performance.

Determining when the vehicle has reached the test termination criterion (departure from speed tolerance for two seconds) is difficult to determine without a driver's aid display which shows these limits on a second-by-second basis. While this point can be determined with some confidence after the test data is analyzed, energy economy cannot be determined if the vehicle is driven past this point. The SAE J1634 procedure further confuses this issue by stating "...speeds lower than those prescribed are acceptable providing the vehicle is operated at maximum available power."

After approximately 15 test cycles, the tires had worn to the extent that they needed replacement, even though we used the best tires available and had $50 \%$ of the tread shaved off to 
curtail tire wear and heating. Twin-roll dynamometers are hard on tires. It is not known to what extent this extreme tire wear affects test results.

The procedure for dynamometer calibration referenced by the SAE J1634 procedure does not apply to electric dynamometers, although the procedure recommends the use of a dynamometer of this type. Each laboratory used its own standard calibration and setup procedure. 


\section{APPENDIX A}

Letter Report - Environmental Protection Agency

A-1 


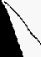


Technical Report

\author{
Testing of an Electric Vehicle on a \\ clayton Water-Brake Chassis Dynamometer
}

by

Ronald M. Schaefer

March 1994

NOTICE

Technical Reports do not necessarily represent final EPA decisions or positions. They are intended to present technical analysis of issues using data which are currently available. The purpose in the release of such reports is to facilitate the exchange of technical information and to inform the public of technical developments which may form the basis for a final EPA decision, position or regulatory action.

U. S. Environmental Protection Agency Office of Air and Radiation

Office of Mobile Sources

office of Regulatory Programs and Technology Technology Development Group

2565 Plymouth Road

Ann Arbor, MI 48105 



\section{MEYORANDUY}

SUBJECT: Exemption From Peer and Administrative Review

FROM:

Karl H. Hellman, Chief Technology Development Group

TO:
Crias I. Gray, Jr., Director $f$
Office of Regulatory Programs and Technology

The attached report entitled "Testing of an Electric Vehicle on a Clayton Water-Brake Chassis Dynamometer" (EPA/AA/TDG/94-01) describes the energy consumption and driving range results obtained from a pure electric vehicle driven over different driving cycles. This testing was part of a round-robin test program with the U.S. Department of Energy, Ford Motor Company, and the California Air Resources Board. This report only describes test results obtained at EPA/NVFEL.

Since this report is concerned only with the presentation of data and its analysis and does not involve matters of policy or regulations, your concurrence is requested to waive administrative review according to the policy outlined in your directive of April 22,1982 .

Concurrence:

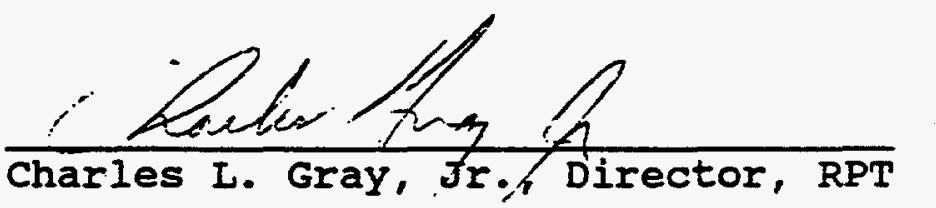

Date:

$$
4-11-94
$$

Attachment

cc: E. Burger, RPT 
. 
I. Summary . . . . . . . . . . . . . . . . . . 1

II. Introduction. . . . . . . . . . . . . . . . . . 1

III. Description of Test Procedures. . . . . . . . . . . . 3

IV. Description of Test Vehicle . . . . . . . . . . . . . 5

v. Test Facilities and Analytical Methods. . . . ... . . 6

VI. Discussion of Test Results. . . . . . . . . . . . . . 7

A. SAE J1634 Energy Consumption Testing . . . . . . . 7

B. Individual City and Highway Energy Consumption Testing. . . . . . . . . . . . . . . . 8

c. Petroleum-Equivalent Fuel Economy Results. . . . . 9

D. SAE J1634 Range Testing. . . . . . . . . . . 11

VII. Future Efforts . . . . . . . . . . . . . . . 11

VIII.Acknowledgements. . . . . . . . . . . . . . . . . . 11

IX. References. . . . . . . . . . . . . . . . 12

Appendix A . . . . . . . . . . . . . . . . . . . A-1 



\section{Summary}

A 1988 Ford Escort Wagon equipped with a lead-acid battery propulsion system was tested for energy consumption and range on a Clayton water-brake chassis dynamometer at the EPA National Vehicle and Fuel Emissions Laboratory in Ann Arbor, Michigan.

Two different test procedures were used to determine energy consumption. The first test procedure followed the newly developed SAE Recommended Practice $\mathrm{J1634}$ for the testing of electric vehicles. Following this procedure will yield only a combined energy consumption value for both the city and highway driving cycles. Therefore, the vehicle was also tested separately over city and highway driving cycles which more closely follow the standard test procedure for conventional vehicles. From this procedure, energy consumption values over the city and highway cycles were determined independently of each other without deviating greatly from the current test and calculation procedures.

Presented in this report are three power consumption values. The first is System AC Energy Consumption, or the amount of power from the electrical wall plug to the on-board vehicle charging system. The second value is system DC Energy Consumption, or the amount of power from the on-board vehicle charging system to the batteries. Both these power values were measured during the battery recharging period after driving the vehicle over various cycles. The last power value measured during this program was Vehicle Net DC Energy Consumption, or the actual amount of power delivered from the batteries for propulsion of the vehicle. This power value was obtained during the actual test procedure driving cycles.

AC energy consumption values with the clayton water-brake dynamometer averaged $504 \mathrm{~W}-\mathrm{hr} / \mathrm{mile}$ over the SAE J1634 test procedure. The values reported here are wall-power numbers and would be the amount of power for which the consumer would need to pay. The city energy consumption value was determined to be $656 \mathrm{~W}-$ $\mathrm{hr} / \mathrm{mile}$, and the highway value was measured to be $489 \mathrm{~W}-\mathrm{hr} / \mathrm{mile}$. By applying the calculation method used in DOE rulemaking that will allow the conversion of individual city and highway energy consumption values into a combined petroleum-equivalent fuel economy value, a fuel economy value of 133.5 MPG was obtained.

\section{Introduction}

The California Air Resources Board (CARB) has mandated that 2 percent of all vehicle sales in that state shall be zero-emitting vehicles by the year 1998.[1] one possible means of obtaining zero pollution at the tailpipe in a conventional passenger vehicle is with the use of a battery-powered propulsion system. 
Since battery-powered vehicles behave differently than conventional internal combustion engine (ICE) vehicles, it was necessary to develop a new test procedure to accurately determine energy consumption and range of electric-powered vehicles. A task force was formed under the Society of Automotive Engineers (SAE) Light-Duty Vehicle Performance and Economy Measurement Standards Committee with the goal of developing a standard test procedure that "establishes uniform procedures for testing electric batterypowered vehicles which are capable of being operated on public and private roads." This procedure is said to "allow for the determination of energy consumption and range based on the Federal Emission Test Procedure (FTP) and the Highway Fuel Economy Test Procedure (HWFET)."[2].

EPA has membership in this committee and followed the development of this SAE procedure. This procedure was developed and finalized, however, without testing any electric vehicles over it to determine if this procedure was reliable and repeatable.

As a result of the need to test an electric vehicle over this procedure to obtain information regarding the procedure's repeatability, a round-robin test program was formed involving the U.S. Department of Energy (DOE), Idaho National Engineering Laboratory (INEL), U.S. EPA, Ford Motor Company, and CARB. Each site agreed to test an electric battery-powered 1988 Ford Escort Wagon for energy consumption and range following the SAE J1634 procedure. EPA tested the vehicle on both a clayton water-brake dynamometer and a Horiba electric dynamometer. EPA also conducted additional testing of the vehicle to obtain separate city and highway energy consumption values. In its current form, the SAE J1634 procedure will only yield a combined city/highway energy consumption value. The electric dynamometer results are not presented in this report but will be published at a later date.

Separate city and highway energy consumption values were required to determine a petroleum-equivalent fuel economy value based on the DOE's rulemaking released on February 4, 1994.[3] The DOE rulemaking allows a combined fuel economy value, to be used in Corporate Average Fuel Economy (CAFE) calculations, to be calculated from individual city and highway energy consumption values. The rulemaking references the SAE J1634 procedure but also requires individual city and highway energy consumption values.

This report contains energy consumption and range results when testing the vehicle over the J1634 procedure. Individual city and highway energy consumption values were also obtained so that a petroleum-equivalent fuel economy value could be determined for this vehicle. All results presented in this report were obtained on a clayton water-brake chassis dynamometer. 


\section{Description of Test Procedures}

The main purpose of this round-robin test program was to test a single electric vehicle at four different sites over the newly developed SAE J1634 test procedure. This procedure addresses battery conditioning, data to be recorded during testing, energy consumption testing, range testing, and coastdown testing.

The batteries were aged by INEL prior to testing at EPA. They were aged to an equivalent mileage of between 2,000 and 6,200 miles, as the procedure requires. INEL discharged the batteries both at a C/3 rate (46 amps for these batteries) on a battery test stand and when equipped on the vehicle. [4] Both methods yielded similar results and proved to be an acceptable method of verifying or measuring battery capacity.

The test procedure requires a substantial amount of data to be recorded from each test. INEL supplied EPA with a data acquisition system that measured the following data requirements over all testing described in this report. The data recorded for each test cycle were:

\section{Actual miles traveled;}

2. System AC Energy Consumption--Watt-hours delivered from the electrical wall socket to the on-board charging system;

3. System DC Energy Consumption--Watt-hours delivered from the on-board charging system to the batteries; and

4. Vehicle DC Energy Consumption--Watt-hours delivered from the batteries to the electric motor for propulsion of the vehicle.

The SAE energy consumption test procedure requires the vehicle to be driven cver two consecutive Urban Dynamometer Driving Schedule (UDDS) cycles separated by a 10-minute soak with the key switch in the "off" position and the test cell fan not operating during this soak period. Immediately following the second UDDS cycle, two Highway Fuel Economy Test (HFET) cycles were driven separated by a 15-second soak with the key switch in the "on" position and the brake pedal depressed.

The SAE procedure requires energy consumption values to be measured during the second HFET cycle only. It was, however, not possible to adhere to this requirement, because the recharge data will automatically reflect two HFET cycles. Therefore, EPA testing deviated from this SAE requirement and measured energY consumption over two UDDS and two HFET cycles. 
The SAE procedure also requires the measurement of a combined UDDS/HFET driving range. The range test requires the vehicle to be driven over two successive UDDS cycles followed by two HFET cycles. A 15-second soak is required between the two HFET cycles followed by a 10-minute soak after the second HFET cycle. The test cell fan was shut off for the 10-minute soak but remained operational for the 15-second soak. This test sequence was repeated until the test termination criteria were met, at which point the vehicle was quickly decelerated to a stop. Extended soaks between each cycle (about 40 seconds), however, resulted due to the fact that the video driver's aid could not be reloaded instantaneously.

The test termination criteria detailed in the SAE procedure were somewhat different from current existing test procedures. With the SAE J1634 procedure, the range test would continue even if the vehicle could not meet the required speed profile provided the vehicle is operated at the maximum available power output during such occurrences. The criteria for termination that ended each range test during EPA testing of the electric vehicle was the requirement to stop the test if the vehicle does not reach $45 \mathrm{MPH}$ after 30 seconds from the 187-second mark and then hold a $45 \mathrm{MPH}$ speed until the 305-second mark of a UDDS cycle. Each range test, therefore, ended at the 217-second mark of the UDDs cycle where a 45 MPH speed could not be attained.

The SAE procedure also describes how coastdown testing of an electric vehicle shall be performed. EPA used coastdown data supplied by INEL for setting up the dynamometer. The complete coastdown curve for this vehicle is supplied in Appendix A of this report. A clayton water-brake dynamometer is not equipped to handle an entire coastdown curve. Therefore, an EPA determination was made to set the actual dynamometer horsepower based on the INEL supplied 55 to 45 MPH coastdown time. The actual dynamometer horsepower setting on the dynamometer control system was adjusted until a time of 23.14 seconds was achieved for coasting from 55 to $45 \mathrm{MPH}$. The resultant actual dynamometer horsepower was $5.26 \mathrm{hp}$.

EPA also tested the electric vehicle over a test procedure more similar to the conventional test procedure that would yield separate city and highway energy consumption values so that a petroleum-equivalent fuel economy value could be calculated. City values were obtained by driving two consecutive UDDS cycles separated by a 10-minute soak with the key switch in the "off" position and the test cell fan off. Similarly, highway values were obtained by driving the vehicle over two successive HFET cycles separated by a 15-second soak period with only the brake pedal depressed.

Both the city and highway cycles were started after soaking the vehicle on charge overnight so that at the beginning of each test cycle, the batteries were at a full charge, similar to the SAE procedure. For the EV tested, the city energy consumption value and the highway energy consumption value were obtained in a slightly different manner than is done for conventional vehicles. 
Because it is not easy to obtain separate "hot" and "cold" energy consumption values for an EV, the subject of how the two UDDS cycles back=to-back compare with the cold/hot weighted approach used for conventional testing should be discussed. In essence, the approach used here has a weighting factor of 0.5 applied to the cold UDDS cycle and 0.5 applied to the hot UDDS cycle. These values are not the same as the 0.43 and 0.57 factors used for the conventional calculation methodology. Whether or not the 50-50 weighting favors, is neutral to, or penalizes EVs with respect to their energy consumption depends on the ratio of the energy consumed by the EV in the cold start cycle to that consumed in the hot start cycle. EVs have a lower ratio then CVs due to the lack of the need for extra fuel (energy) to start the vehicle and the substantially lower energy requirement to warm up the system to operate more efficiently. For example, fuel (energy) rate delivered to an engine is higher during the time it is warming up and reduces to the lower "hot" rate only after the coolant temperature exceeds a certain value. No similar losses exist for EVs. Both vehicles suffer losses caused by excess friction in the drivetrain during warmup. Because EVs have a more favorable cold to hot energy consumption ratio, running two UDDs cycles back to back allows this warmup benefit to be reflected in the test result.

If the energy consumed driving the latter part of the second UDDS test ("Bag 4" in conventional vehicle nomenclature) is lower than that consumed in the latter portion of the first uDDs cycle, then the EV would be treated favorably by the way these tests were run, since for conventional vehicles the assumption is made that the two portions (Bag 2 and Bag 4 ) of the test are identical.

For the highway cycle fuel economy determination, conventional vehicles are operated through two highway cycles. In order to reduce variability and obtain the highest MPG value, only the second of the two cycles is used for determining the MPG value even though both cycles are run "hot." This is easy to do with conventional vehicles since the fuel consumed is determined by a carbon balance of the exhaust emissions and so only the second test is sampled. With EVs, however, there isn't any convenient way to not count the energy consumed during the first highway cycles, so the way the tests were run is very slightly unfavorable to the EV.

Further study of these test procedure nuances may be warranted if the SAE procedure is revised to permit the separate determination of city and highway energy consumption. No adjustments to the data in this report have been made, and if any were contemplated, they would be quite small.

IV. Description of rest vehicle

The test vehicle used for this round-robin test program was a 1988 Ford Escort Wagon equipped with a manual transmission and radial tires. The vehicle was tested at an equivalent test weight of $4,250 \mathrm{lbs}$ and an actual dynamometer horsepower of 5.26 . 
The venicie was converted to electric propulsion for DOE by soleq Corporation. The system consists of $i 3$ b-volt sealed leadacid Sonnenschein satteries (Model lo. DF-i60) iith a singie electric notor.

A picture or this test vehicle is provided in Eigure 1 below.

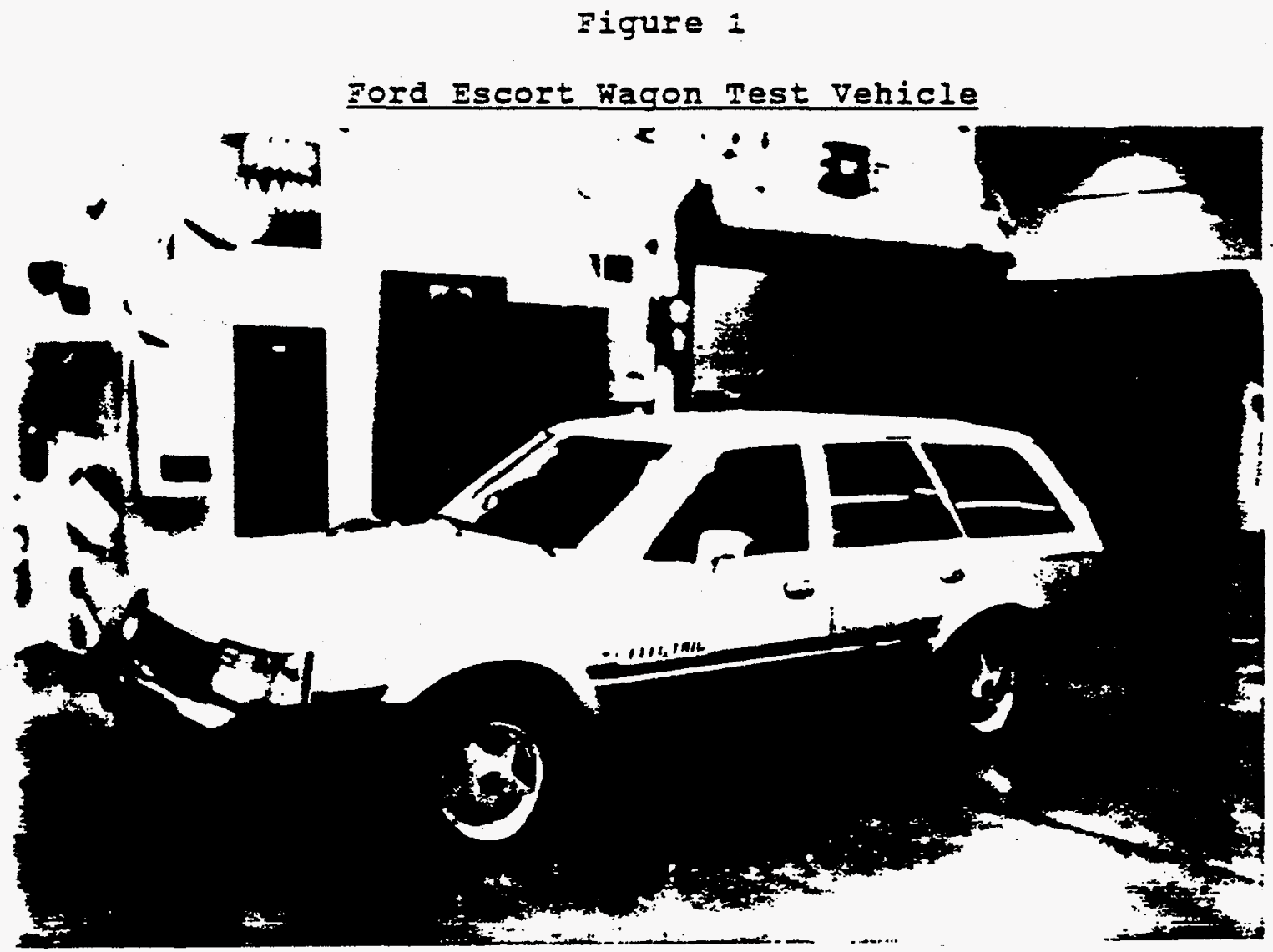

V. Test Facilities and Analytical Methods

EPA testing was conducted on a water-brake Clayton model ECE50 double-roll chassis dynamometer using a direct-drive variable inertia flywheel unit and road load power control unit. The vehicle was equipped with its own charging system. The vehicle was recharged from a wall socket providing 125 volts at 20 amps. This amount of recharge power was ample to recharge the battery pack to a full state-of-charge during an overnight soak period.

The data acquisition system used in this test program to measure power consumption and vehicle miles travelled was provided to EPA with the test vehicle from the Idaho National Engineering Laboratory. This system measured power consumed during both vehicle testing and vehicle charging periods. Voltage and amperage data was acquired every $100 \mathrm{milliseconds}$ but was not stored at this rate. The 100-millisecond data was averaged over the storage period, which was 1 second for vehicle testing and 1-minute for vehicle charging. 
VI. Discussion of Test Results

\section{A. SAE J1634 Energy Consumption Testing}

The Escort electric vehicle was first tested over the SAE J1634 Energy Consumption Procedure. This testing yielded a combined city/highway energy consumption value. Table 1 includes the results from EPA testing on a clayton water-brake dynamometer.

\begin{tabular}{|c|c|c|c|}
\hline $\mathrm{BAB}$ J1634 EI & $\begin{array}{r}\text { rable } 1 \\
\text { IgY Consump }\end{array}$ & on Test Resu & ts \\
\hline Nater-Brake Dynamometer: & $\begin{array}{c}\text { system AC } \\
(\mathrm{T}-\mathrm{hr} / \mathrm{mile}) \\
\end{array}$ & $\begin{array}{c}\text { 8ystem DC } \\
(\overline{T-h r / m i l e)}\end{array}$ & $\begin{array}{c}\text { Vebicle ret DC } \\
(\pi-h r / m i l e)\end{array}$ \\
\hline Test $\# 1$ & 468 & 339 & 259 \\
\hline Test $\# 2$ & 540 & 378 & 264 \\
\hline Average & 504 & 358 & 262 \\
\hline
\end{tabular}

All results presented in Table 1 are in watt-hours per mile

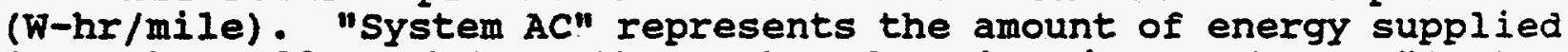
from the wall outlet to the on-board recharging system. "system DC" represents the amount of power delivered from the on-board charging system to the batteries. "Vehicle Net DC" represents the amount of overall power delivered from the batteries during driving with the amount of energy generated from regenerative braking subtracted.

From the water-brake chassis dynamometer results, the two tests conducted differ substantially when considering system $A C$ and DC power usage. The two power levels differ by 15 and 12 percent respectively between the two individual tests. The net DC results correspond very well, however, with only a 2 percent difference. From these results, it can also be seen that a substantial amount of power from the wall socket is apparently lost in the on-board charging system. An average of $18.4 \mathrm{~kW}-\mathrm{hr}$ from the wall socket results in only $13.1 \mathrm{~kW}-\mathrm{hr}$ being supplied to the batteries. This would seem to indicate that the charging system on this vehicle is only about 71 percent efficient. This results in a substantial penalty in a petroleum-equivalent fuel economy value since the calculation is based on wall-power values. A more efficient charging system would increase calculated fuel economy results.

The differences between "System DC" and "Vehicle Net DC" power values result from battery inefficiency. The average "Vehicle Net DC" power consumed over the SAE procedure was $9.5 \mathrm{kw}-\mathrm{hr}$. Compared to the wall-power usage of $18.4 \mathrm{~kW}-\mathrm{hr}$, the overall vehicle energy efficiency from wall to battery-out is approximately 52 percent 
when considering charging system and battery inefficiencies. The amount of energy delivered to the batteries during this driving cycle from the use of regenerative braking was approximately 0.6 $k w-h r$ and will be reflected in all three power consumption values.

\section{B. Individual City and Highway Energy Consumption Testing}

The vehicle was tested at EPA over separate city and highway test cycles to determine individually the city and highway energy consumption values for this vehicle. The city values were obtained by running two successive UDDs cycles separated by a 10-minute soak. The results obtained from this testing are presented in Table 2 below. Again, all values are in watt-hours per mile.

\begin{tabular}{|c|c|c|c|}
\hline \multicolumn{4}{|c|}{$\begin{array}{l}\text { Table } 2 \\
\text { Consumpt }\end{array}$} \\
\hline Water-Brake Dynamometer: & $\begin{array}{c}\text { 8ystem AC } \\
(\mathrm{w}-\mathrm{hr} / \mathrm{mile})\end{array}$ & $\begin{array}{c}\text { system DC } \\
(\bar{n}-\mathrm{hr} / \mathrm{mile})\end{array}$ & $\begin{array}{c}\text { Vehicle Net DC } \\
(\text { th-hr/mile })\end{array}$ \\
\hline Test $\neq 1$ & 670 & 428 & 303 \\
\hline Test $\# 2$ & 642 & 395 & 303 \\
\hline Average & 6.56 & 412 & 303 \\
\hline
\end{tabular}

The deviations in individual test results are less than those acquired during the J1634 testing. System AC and DC results differ between individual tests by only 4 and 8 percent respectively accompanied by no deviation in vehicle net DC power usage between tests. Again, large inefficiencies were noted during this testing with the on-board recharging system and the batteries. The wallpower used during this testing averaged $9.8 \mathrm{kw}-\mathrm{hr}$, and the amount of power supplied to the batteries during recharging averaged 6.2 $k W-h r$ resulting in a recharging efficiency of 63 percent. During this driving cycle, the "battery-out" power averaged $4.5 \mathrm{~kW}-\mathrm{hr}$. When comparing this value to the wall-power, an overall battery power efficiency of 46 percent is achieved.

The electric vehicle was next tested to obtain a highway energy consumption value. The driving schedule used here was two successive HFET cycles separated by a 15-second soak period. Table 3 below presents the results obtained from this testing. All values are presented in watt-hours per mile. 


\begin{tabular}{|c|c|c|c|}
\hline Highway cycle & Energy Consum & ion Test Re & 11 ts \\
\hline Water-Brake Dynamor & $\begin{array}{c}\text { 8ystem AC } \\
(\overline{n-h r / m i l e)} \\
\end{array}$ & $\begin{array}{c}\text { 8ystem DC } \\
(\pi-b r / m i l e) \\
\end{array}$ & $\begin{array}{c}\text { Vehicle Net DC } \\
(\mathrm{T}-\mathrm{hr} / \mathrm{mile})\end{array}$ \\
\hline Test \#1 & 564 & 346 & 222 \\
\hline Test $\# 2$ & 463 & 287 & 220 \\
\hline Test \#3 & 441 & 286 & 217 \\
\hline Average & 489 & 306 & 220 \\
\hline
\end{tabular}

A third test was conducted during this phase due to the rather large discrepancy between the results from the first two tests. All three tests, however, were included in presenting an average value.

These results again indicate a rather large inefficiency in the on-board charging system. The wall-plug power used for these three tests averaged approximately $10.4 \mathrm{~kW}-\mathrm{hr}$. The corresponding amount of power supplied to the batteries during recharging averaged $6.5 \mathrm{~kW}-\mathrm{hr}$, a recharge efficiency of 62 percent.

When driving over two successive HFET cycles, the brakes are only applied four times. Therefore, the amount of power supplied to the batteries during driving by the regenerative braking system should be very small. The overall battery efficiency obtained here for "wall to battery-out" is approximately 45 percent. (The "Vehicle Net DC" power used averaged $4.7 \mathrm{kw}-\mathrm{hr}$ for this testing.)

\section{Petroleum-Equivalent Fuel Economy Results}

Using the recent DOE rulemaking entitled "Electric and Hybrid Vehicle Research, Development, and Demonstration Program; Equivalent Petroleum-Based Fuel Economy Calculation,"[3] a petroleum-equivalent fuel economy value can be calculated for this electric vehicle. The only requirements needed for this calculation are the city and highway energy consumption values presented in the previous section.

The DOE rulemaking references the SAE J1634 test procedure for obtaining energy consumption values for an electric vehicle; SAE procedure J1634 will only allow for a combined city/highway energy consumption value to be measured. EPA tested the electric vehicle separately over city and highway driving cycles so that these energy consumption values could be determined independently of each other. 
Presented here is a step-by-step petroleum-equivalent fuel economy calculation resulting from EPA testing on the water-brake chassis dynamometer and the use of the method outlined in the DOE rulemaking.

$$
\begin{aligned}
& \text { City energy consumption }=0.656 \frac{\mathrm{kW}-\mathrm{hr}}{\mathrm{mile}}=1.524 \frac{\mathrm{mile}}{\mathrm{kW-hr}} \\
& \text { Highway energy consumption }=0.489 \frac{\mathrm{kW}-\mathrm{hr}}{\mathrm{mile}}=2.045 \frac{\mathrm{mile}}{\mathrm{kW-hr}} \\
& \text { City fuel economy }=1.524 \frac{\mathrm{mile}}{\mathrm{kW}-\mathrm{hr}} \times 33.44 \frac{\mathrm{kW}-\mathrm{hr}}{\mathrm{gallon}}=50.963 \mathrm{MPG} \text { gasoline-equiv. } \\
& \text { Highway fuel economy }=2.045 \frac{\mathrm{mile}}{\mathrm{kW}-\mathrm{hr}} \times 33.44 \frac{\mathrm{kW}-\mathrm{hr}}{\mathrm{gallon}}=68.385 \mathrm{MPG} \text { gasoline equiv. }
\end{aligned}
$$

It should be noted that the value for the $\mathrm{kw}-\mathrm{hr}$ of gasoline galion

used here differs from the value suggested by DOE. The value used here is consistent with the value used by EPA in other fuel economy rulemakings that involve fuel energy content.

After applying the factor for converting a kilowatt-hour value into equivalent gallons of gasoline, a composite fuel economy value for the electric vehicle can be determined based on the 55/45 method used for CAFE calculations.

$$
\begin{aligned}
& \text { MPG composite }=\frac{1}{\frac{.55}{M P G_{\text {city }}}+\frac{.45}{M P G_{\text {hwy }}}} \\
& \text { MPG } \\
& =\frac{\frac{.55}{50.963}+\frac{.45}{68.385}}{\text { composite }} \quad 57.562 \text { MPG gasoline equiv. }
\end{aligned}
$$

Now, it is necessary to apply the Petroleum Equivalency Factor (PEF) found in the DOE rulemaking for an overall petroleumequivalent fuel economy for this electric vehicle.

$$
\begin{aligned}
& \mathrm{MPG}_{E V}=\mathrm{MPG}_{\text {composite }} \times \mathrm{PEF} \\
& \mathrm{MPG}_{\mathrm{EV}}=57.562 \times 2.32=133.5
\end{aligned}
$$

Therefore, the value that would used for this electric vehicle in any calculations of a manufacturer's average fuel economy would be 133.5 miles per gallon. 


\section{BAB J1634 Range Testing}

The last phase of testing with this electric vehicle consisted of range testing following the protocols outlined in the SAE J1634 test procedure. The vehicle was driven over successive UDDS and HFET driving cycles until the test termination point was reached. The driving cycles and test termination point are described in more detail in section III of this report.

The SAI procedure is written such that the range test shall continue if the vehicle cannot meet the driving trace just as Icng as the vehicle is operated at maximum power output. The criteria that ended the range test at EPA was where the procedure states that "if the vehicle cannot attain 45 miles per hour 30 seconds after the 187-second in the UDDS cycle, the test shall be terminated." At the 217-second mark of the third UDDs driving cycle (after two previous UDDS cycles and two HFET cycles), the vehicle speed was not $45 \mathrm{MPH}$, the vehicle was quickly decelerated to stop, and the range determined. The resultant range was measured as 37.8 miles. INEL informally reported a similar range result to EPA.

\section{Future Efforts}

The electric vehicle is currently being tested at EPA on a Horiba 48-inch single-roll electric chassis dynamometer over the same test sequence described in this report. These results will be published in a separate EPA technical report when testing is completed.

The vehicle will then be tested at Ford Motor Co. and CARB. INEL will then publish a report describing all the results from testing at the four sites included in this round-robin test program.

\section{Acknowledgements}

The authors would like to acknowledge the cooperation and support of George $\mathrm{H}$. Cole and Roger A. Richardson of the Idaho National Engineering Laboratory for supplying EPA with the test vehicle and the data acquisition system.

The authors also appreciate the efforts of James Garvey, Ray ouillette, Rodney Branham, Robert Moss, and Carl Fuller of the Testing support Branch who conducted the driving cycle tests and data acquisition. The word processing and editing efforts of Jennifer Criss and Lillian Johnson of the Technology Development Group are also appreciated. 


\section{References}

1. "Proposed Regulations for Low-Emission Vehicles and clean Fuels--staff Report," State of California Air Resources Board, August 1990.

2. "Electric Vehicle Energy Consumption and Range Test Procedure," SAE Surface Vehicle Recommended Practice, SAE J1634, 1993.

3. "Electric and Hybrid Vehicle Research, Development, and Demonstration Program; Equivalent Petroleum-Based Fuel Economy Calculation," 10 Code of Federal Regulations, Part 474, Docket No. EE-RM-94-101, February 4, 1994.

4. Letter from George H. Cole, Program Manager, Electric and Hybrid Vehicle Program, INEL to Ronald M. Schaefer, Mechanical Engineer, U.S. EPA, February 7, 1994. 


\section{Appendix A}

Ford Escort Electric Vehicle coastdown Data

\begin{tabular}{c} 
8peed \\
(MPE) \\
\hline 60 \\
59 \\
58 \\
57 \\
56 \\
55 \\
54 \\
53 \\
52 \\
51 \\
50 \\
49 \\
48 \\
47 \\
46 \\
45 \\
44 \\
43 \\
42 \\
41 \\
40 \\
39 \\
38 \\
37 \\
36
\end{tabular}

$$
\begin{aligned}
& \text { Time } \\
& \text { (sec) } \\
& \hline 0.00 \\
& 1.88 \\
& 3.80 \\
& 5.77 \\
& 7.77 \\
& 9.82 \\
& 11.92 \\
& 14.06 \\
& 16.24 \\
& 18.48 \\
& 20.76 \\
& 23.10 \\
& 25.48 \\
& 27.92 \\
& 30.41 \\
& 32.96 \\
& 35.56 \\
& 38.22 \\
& 40.94 \\
& 43.73 \\
& 46.57 \\
& 49.47 \\
& 52.44 \\
& 55.47 \\
& 58.57
\end{aligned}
$$

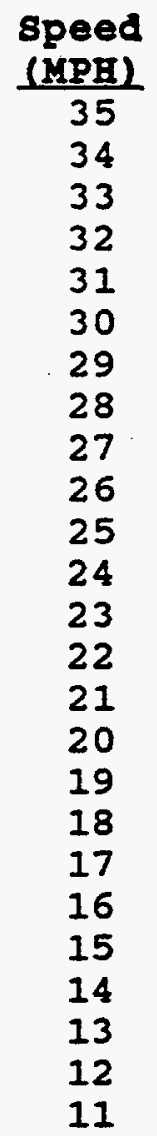

\begin{tabular}{c} 
Time \\
(sec) \\
\hline 61.73 \\
64.96 \\
68.27 \\
71.64 \\
75.08 \\
78.59 \\
82.17 \\
85.82 \\
89.55 \\
93.35 \\
97.22 \\
101.16 \\
105.17 \\
109.26 \\
113.41 \\
117.64 \\
121.93 \\
126.29 \\
130.72 \\
135.21 \\
139.76 \\
144.38 \\
149.05 \\
153.77 \\
158.54
\end{tabular}

Inertia Wt. $=4,250$ lbs

$$
\begin{aligned}
& \mathrm{f}^{\prime} \mathrm{O}=38.7385 \mathrm{lb} \quad \mathrm{Miw}=132.09423 \\
& f^{\prime} 2=0.0186 \mathrm{lb} / \mathrm{MPH}^{\wedge} 2 \quad \mathrm{Mdlc}=1.9814135
\end{aligned}
$$
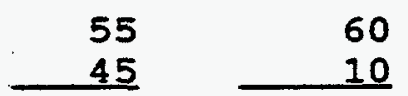

Speed (MPH)

60

50

40

30

20

10
Power (BD)

16.91

11.36

7.31

4.44

2.46

1.08
(Power (kTi)

12.61

8.47

5.45

3.31

1.84

0.81 



\section{APPENDIX B}

\section{Letter Report - Ford Motor Company}





\title{
ELECTRIC VEHICLE ROUND-ROBIN TESTING
} USING SAE RECOMMENDED PRACTICE J1634 Ford Motor Company Certification Test Laboratory

\author{
Michael J. Fuher \\ Correlation Engineering Dept. \\ August, 1994
}





\section{ELECTRIC VEHICLE ROUND-ROBIN TESTING USING SAE RECOMMENDED PRACTICE J1634 Ford Motor Company Certification Test Laboratory}

\section{SUMMARY}

SAE Recommended Practice J1634 was the test procedure used to test the EVcort electric vehicle at Ford in July, 1994 for energy consumption (EC) and range. Data from the EC and range tests include:

- System EC $=466.12$ AC Watt-hrs/mile

- System EC $=347.33$ DC Watt-hrs/mile

- $\quad$ Net Vehicle EC $=268.27$ DC Watt-hrs/mile

- Gross Vehicle EC $=288.32$ DC Watt-hrs/mile

- Range (when the termination criteria were met) $=45.03$ miles

This report also fulfills all other reporting requirements specified in Practice J1634, including identification information on the vehicle and any deviations from Practice $\mathrm{J} 1634$. that occurred during testing. Also included in this report are discussions on the shortcomings that were discovered in Practice J1634. Several issues were noted including comments on soak time limitations and test termination criteria. Other issues were also addressed, especially the issue that the EVcort was underloaded by $20 \%$ when tested on a dynamometer during this test program.

\section{INTRODUCTION}

In July, 1994, the battery-powered "EVcort" electric vehicle was tested per the newly developed SAE Recommended Practice J1634 (May, 1993) at the Certification Test Laboratory (CTL) of Ford Motor Company in Dearborn, Michigan.

The testing conducted at CTL was part of a jointly-sponsored government/industry round-robin correlation test program. The facilities scheduled to test the EVcort as part of this program are:

- Idaho National Engineering Laboratory (INEL)
- $\quad$ Ford MPA's National Vehicle and Fuel Emissions Laboratory (NVFEL)
- Southwest Research Institute
- California ARB's Haagen-Smit Laboratory

The objectives of the round-robin test program are to:

- Use its results to improve the test procedure methodology

- Correlate the data acquired with other test laboratories

- Gain experience in testing electric vehicles

- Identify the shortcomings or lack of clarity in Practice J1634 


\section{IDENTIFICATION INFORMATION}

Vehicle ("EVcort")

- $\quad 1988$ Ford Escort station wagon converted to an electric vehicle

- $\quad$ Broken odometer stuck at 29,864 miles

- Front axle weight (drive axle):

2021 lbs. - actual

$2176 \mathrm{lbs}$. - as tested (i.e. with driver and weight bags

totalling to an additional 300 lbs. in front)

- Total vehicle weight:

4042 lbs. - actual

$4344 \mathrm{lbs}$. - as tested (i.e. with driver and weight bags

totalling to an additional $300 \mathrm{lbs}$. in front)

- Tires:

Michelin radial XGT $P 175 / 65 R 14$

Pressure set at $45 \mathrm{psi}$

- Motor:

General Electric separately-excited dc

32 kW @98 V peak power

$6000 \mathrm{rpm}$ maximum speed

$191 \mathrm{~N}-\mathrm{m}$ maximum torque

- Soleq controller, 400 A maximum current

- Transmission:

Production Ford 5-speed manual transaxle

Gear. ratios (1st-5th respectively): $3.60,2.12,1.39,1.02,0.77$

Differential final drive ratio: $3.33: 1$

Shift points for CTL testing:

2nd gear (0-45 $\mathrm{mph})$

3rd gear (45-65 $\mathrm{mph})$

\section{- Battery System}

18 6-volt Sonnenschein lead-acid batteries

7 under hood; 11 in rear

Batteries \#4,5 (under hood) were replaced just before testing began with 2 cycled batteries of the same make as the other 16 non-replaced batteries. The former Battery \#4 had failed upon arrival, and the greater size (newer model battery) of former Battery \#5 prevented the hood to close.

- Nominal capacity rating:

160 amp-hrs @ C/5 discharge rate

138 amp-hrs@ @ /3 discharge rate 
- Dynamometer

- $\quad$ All testing done on Cell \#4 (except for first $\mathrm{C} / 3$ test, on Cell \#1)

- $\quad 8.65^{\prime \prime}$ twin-roll hydrokinetic dynamometers

- $\quad 17^{\prime \prime}$ between roll axes

- Vehicle restrained with the fan's bumpers at the front of the vehicle, rear tire chocks, and the emergency brake

- $\quad 4250 \mathrm{lbs}$. test inertia weight (4095\# on front roll, 155\# on rear roll)

- $\quad 6.0$ actual horsepower (4.0 indicated $\mathrm{hp}$ )

- $\quad$ Site altitude: 603 feet above sea level

- Site temperature: $68^{\circ} \mathrm{F}-86^{\circ} \mathrm{F}$

\section{TEST PROCEDURES}

Practice $\mathrm{J} 1634$ established uniform test procedures for electric vehicles, which allows for the determination of energy consumption and range. Practice $\mathrm{J1634}$ specifies dynamometer test procedures to minimize test-to-test variations and to adhere to standard industry practice. Before testing can begin on a dynamometer, Practice J1634 requires that the road load force on the vehicle (as a function of vehicle velocity) must be determined, so that accurate simulation of the road load force on a chassis dynamometer can be accomplished. Practice J1634 also requires that immediately following the completion of vehicle testing, the battery ampere-hour capacity shall be verified.

The sequence of testing performed at CTL can be identified in the following order:

- Dynamometer road-load simulation determination (i.e. coastdown testing)

- Energy consumption testing

- Range testing

- Battery ampere-hour capacity determination (i.e. $\mathrm{C} / 3$ testing)

In sections that follow, the data collected from each test sequence will be described. Deviations from Practice J1634, as well as its shortcomings will also be described.

\section{DYNAMOMETER ROAD LOAD SIMULATION DETERMINATION}

The actual horsepower (AHP) determined for the EVcort at CTL was $6.00 \mathrm{hp}$. On CTL's Cell 4, for example, this would corresponded to the sum of 4.00 indicated horsepower (IHP), 1.78 frictional horsepower (FHP), and 0.22 rear-roll horsepower (RRHP). This determined AHP value was used for all EVcort testing at CTL.

Section 8.2 of Practice 11634 requires that the AHP is to be determined according to SAE Recommended Practice J1263 (May, 1984). Practice J1263 is divided into two parts. Part One describes the procedures necessary to determine the road load force 
profile. Part Two describes the procedures necessary to determine the dynamometer horsepower setting, based on the road load force profile determined in Part One.

Based on an intra-EPA memorandum (Bruetsch to Hellman, July 6, 1993) it was agreed that Part One of Practice. J1263 need not be performed by each laboratory in this test program. Instead, the road load profile would be provided to each laboratory by INEL. The road load profile was sent by INEL to CTL via telecopier transmittal (Cole to Webb, November 16, 1993).

It is important to note that calculation errors were discovered in the telecopier transmittal that contained the road load profile information. This discovery was made after the round-robin testing at INEL and at NVFEL were already completed, and before the testing at CTL had begun. The averages for the $f_{0}$ and the $f_{2}$ values were each erroneously determined by dividing the sum of four numbers by five, instead of four. With this error, the road load profile used was only $80 \%$ of the true road load profile, which would result in the dynamometer underloading the EVcort by $20 \%$. Furthermore, the road load profile is based on data taken several years ago when the EVcort had a different weight with heavier batteries. All of this information was brought to the attention of INEL personnel. It was subsequently agreed that CTL use the same profile used by INEL and NVFEL in determining the dynamometer horsepower setting, so that the CTL data can be compared with data obtained from these laboratories. In light of the $20 \%$ underloading, any data from this test program that would indicate surprisingly excellent performance of the EVcort must be discounted.

Using the road load profile, Part Two of Practice $\mathrm{J} 1263$ was performed at CTL on the EVcort to determine the dynamometer horsepower setting. The goal of this procedure was to determine the AHP that would allow the EVcort to coast down (in neutral) on a dynamometer from $55 \mathrm{mph}$ to $45 \mathrm{mph}$ in 23.14 seconds. After trying out several AHP settings, $6.00 \mathrm{hp}$ was determined to be the correct AHP setting.

It is important to note that during these coastdowns, the EVcort never reached a stable condition that could yield repeatable data. Section 8.2.1 of Practice J1634 requires that vehicle regenerative braking be disabled during coastdown testing. This was not possible to do on the EVcort, and may have contributed to its instability during coastdown testing. Nonetheless, the coastdown data showed that the $6.00 \mathrm{hp}$ setting was the best AHP estimate to achieve a coastdown time of 23.14 seconds.

\section{ENERGY CONSUMPTION TESTING}

The EC testing data are summarized in Table 6.1. Two EC tests were performed on the EVcort at CTL, both of which started with the vehicle's batteries at $100 \%$ state of charge (SOC). Test \#1 began on July 12 at $9: 30 \mathrm{AM}$, and Test \#2 began on July 15 at 8:40 AM. Both of these tests were performed in Cell \#4 on twin-roll hydrokinetic dynamometer rolls with a test inertia weight of $4,250 \mathrm{lbs}$. and an AHP of $6.0 \mathrm{hp}$. 
Table 6.1 - EC Testing Data

\begin{tabular}{||l||c|c||c|}
\hline Measurements & Test \#1 & Test \#2 & Average \\
\hline Net Vehicle EC (DC Watt-hrs/mile) & 266.41 & 270.12 & 268.27 \\
\hline Net Vehicle EC (AC Amp-hrs) & 70 & 70 & 70 \\
\hline Gross Vehicle EC (DC Watt-hrs/mile) & 287.97 & 288.66 & 288.32 \\
\hline Gross Vehicle EC (AC Amp-hrs) & 74.45 & 74.77 & 74.61 \\
\hline System Charging EC (AC Watt-hrs/mile) & 463.66 & 468.57 & 466.12 \\
\hline System Charging EC (DC Watt-hrs/mile) & 342.37 & 352.28 & 347.33 \\
\hline System Charging EC (DC Amp-hrs) & 104.6 & 106.2 & 105.4 \\
\hline Charge Time (hr:min) & $12: 52$ & $12: 07$ & 12.30 \\
\hline
\end{tabular}

The EVcort is equipped with regenerative braking, which returned energy back to the batteries whenever the brakes were applied. The "Net Vehicle EC" therefore is the difference between the energy taken from the batteries during driving and the energy returned to the batteries during braking. The "Gross Vehicle $E C^{\prime}$ " is the energy taken from the batteries during driving when the vehicle was not braking (i.e., accelerating, cruising, and idling). The top four measurements in Table 6.1 concern data taken during the EC tests. The bottom four measurements concern data taken during the charge that immediately followed EC testing.

Some of the EC measurements are in "per mile" units. The Net and Gross Vehicle EC measurements refer to the distance of the two UDDS cycles plus the distance of the second of the two HWFET cycles. Thus, no data from the first of the two HWFET cycles was included in these measurements, as Practice $\mathrm{J1634}$ requires. These "3-cycle" distances were 25.75 miles and 25.84 miles for Tests \#1 and \#2, respectively. The System Charging EC measurements refer to the total distance traveled for all four cycles. These "4-cycle" distances were 36.32 miles and 36.42 miles for Tests \#1 and \#2, respectively.

The EVcort is equipped with a charging system that cycles off and on after the vehicle is fully charged. The System Charging EC measurements in Table 6.1 do not include data taken during any time after the vehicle was first fully charged, or when the charger was in the cycling mode. The Charge Times in Table 6.1 are the times it took for the battery system to first reach $100 \%$ SOC.

CTL was prepared to perform the first EC test on Monday, July 11. However, the vehicle began soaking on Friday, July 8 . Because Practice J1634 requires that the maximum soak time is 36 hours, a Monday test would have been impossible. Instead, the vehicle was driven outside for about 5 minutes on Monday for the purpose of starting a new soak period. This soak time requirement is used for today's testing of 
conventional vehicles. The necessity for its inclusion for electric vehicle testing must be seriously reconsidered in light of its original intent for gasoline-fueled vehicle testing.

Practice J1634 does not specify whether the hood should be opened or closed or whether the fan should be turned on or off during the soak period following the second UDDS cycle. Practice J1634 does make these specifications for the soak period following the first UDDS cycle in Section 6.3.2. At CTL, it was decided that the hood be closed and the fan be turned off during test soak periods.

\section{RANGE TESTING}

The Range Test data are summarized in Table 7.1. One Range Test was performed on the EVcort, and the batteries were at 100\% SOC at the start of the test. The test began on July 13 at 9:45 AM in Cell \#4 on twin-roll hydrokinetic dynamometer rolls. The test inertia weight was $4,250 \mathrm{lbs}$., and the AHP was $6.0 \mathrm{hp}$. The measurements in Table 7.1 that are in "per mile" units refer to the total distance of the Range Test, i.e., 45.03 miles.

Table 7.1 - Range Testing Data

\begin{tabular}{|l|c|}
\hline Measurements & Data \\
\hline \hline Range (Miles) & 45.03 \\
\hline $\begin{array}{l}\text { Number of } \\
\text { Cycles }\end{array}$ & $\begin{array}{c}3.161 \text { UDDS Cycles + } \\
2 \text { HWFET Cycles }\end{array}$ \\
\hline $\begin{array}{l}\text { Test Termination } \\
\text { Criteria Used }\end{array}$ & $\begin{array}{c}\text { Inability to reach 45 MPH, } \\
217 \text { seconds into a UDDS }\end{array}$ \\
\hline \hline Net Vehicle EC (DC Watt-hrs/mile) & 260.49 \\
\hline Net Vehicle EC (AC Amp-hrs) & 121 \\
\hline Gross Vehicle EC (DC Watt-hrs/mile) & 282.15 \\
\hline Gross Vehicle EC (AC Amp-hrs) & 129.94 \\
\hline System Charging EC (AC Watt-hrs/mile) & 471.69 \\
\hline System Charging EC (DC Watt-hrs/mile) & 356.79 \\
\hline System Charging EC (DC Amp-hrs) & 133.9 \\
\hline Charge Time (hr:min) & $14: 32$ \\
\hline
\end{tabular}


Section 7.3 of Practice J1634 describes the criteria for terminating the Range Test. However, this section was unclearly written, which obscured both the spirit and the intent of the termination criteria..

- The major test termination criterion for the Range Test is "the vehicle's inability to accelerate fast enough to meet the specified speed profile within $2 s$ of the specified time". This statement is inconsistent with Section 5.3, which states, "speeds lower than those prescribed are acceptable provided the vehicle is operated at maximum available power during such occurrences". It is unclear whether or not the "2-second" termination criterion of Section 7.3 supersedes the "maximum output" acceptability criterion of Section 5.3.

- Section 7.3 states that the "2-second" termination criterion does not apply under certain .high-speed conditions. However, there are no clear definitions of what those high-speed conditions are. The phrase "except under the following highspeed conditions" in Section 7.3 should be followed by clear definitions of these conditions. Instead, it is followed by two unclear sentences:

- The first of these sentences refers to the "164-second mark" and the "187second mark" of the UDDS cycle, neither of which adds any helpful information to the definition of high-speed conditions. It states, "Starting at the 164-s mark of the UDS, the test shall be terrninated if the vehicle cannot attain a minimum speed of $72 \mathrm{~km} / \mathrm{h}$ ( $45 \mathrm{mph}$ ) within $30 \mathrm{~s}$ after the 187-mark and then hold that speed until the 305-s mark". This sentence could be better stated, "The time between the 217-second mark and the 305-second mark of the UDDS is a high-speed condition. During this time the test shall be terminated if the vehicle cannot attain a minimum speed of $45 \mathrm{mph}$, assuming that is indeed the true intention of this criterion.

- $\quad$ The second sentence states, "For the HWFET cycle, the test shall be terminated if the vehicle cannot maintain a minimum speed of $72 \mathrm{~km} / \mathrm{h}(45$ $m p h)^{\prime}$. Obviously, there are times during the HWFET cycle when the speed should not be $45 \mathrm{mph}$. This sentence suggests that the test shall be terminated the very moment the HWFET cycle begins, when the vehicle is accelerating from rest, which is a speed that is less than $45 \mathrm{mph}$. Does it really mean, instead, to terminate the test if the vehicle cannot attain $45 \mathrm{mph}$ during those times that the vehicle should be at $45 \mathrm{mph}$ on the HWFET? It is also unclear whether the minimum speed the sentence refers to is for those times when the lower speed tolerance is at least $45 \mathrm{mph}$ or when the scheduled speed is at least $45 \mathrm{mph}$. Furthermore, it is not explicit whether or not this second sentence is attempting to define a high-speed condition.

- Following these two sentences (just describe above), it states, "the vehicle shall at all times be operated at its maximum possible level of performance in the attempt to follow the standard velocity/time profile". This statement suggests that the driver must always depress the accelerator to the maximum position, even during cruises, decelerations, idles, and even braking. 
Section 7.3 needs to be rewritten so that a clear and consistent interpretation of this test procedure will be made.

At CTL, the "2-second" termination criterion was disregarded because the cell computers are not set up to measure the amount of time that the speed is outside of tolerance. The monitor that the driver views during a test displays neither the upper nor the lower speed tolerance, only the scheduled speed. The only termination criterion used at CTL was whether or not the speed of the vehicle was at least $45 \mathrm{mph}$ between the 217-second mark and the 305-second mark of the UDDS. This was the only time window in which the test could possibly be terminated. At the 217-second mark of the fourth UDDS cycle, after having completed two HWFET cycles as well, the vehicle's speed was not at least $45 \mathrm{mph}$, and the test was then terminated.

\section{BATTERY AMPERE-HOUR CAPACITY DETERMINATION}

The ampere-hour capacity of the battery system was determined twice at CTL. On July 8 , the capacity was determined to be 139 Amp-hrs. On July 18, after all testing at CTL had been completed, the capacity was determined to be 138 Amp-hrs. These data compare favorably against the manufacturer's rating of 138 Amp-hrs.

Practice J1634 contains no procedure in performing this determination, nor does it refer to some other procedure to accomplish this determination. Nonetheless, Section 3.2.2 requires that it be performed. In that section, it states, "the capacity shall be verified against manufacturer's rating, by constant current discharge at the $\mathrm{C} / 3$ rate". This is why this determination is sometimes called the " $\mathrm{C} / 3$ Test". The $\mathrm{C} / 3$ rate is the discharge rate at which the battery system is discharged $85 \%$, from full capacity, in three hours.

At $C T L$, the determination was performed by following instructions given by INEL, which required that a person drive the EVcort for three hours on the dynamometer rolls maintaining a constant speed without any breaks or interruptions. This long procedure took its toll on the drivers causing painful cramps in the legs and feet from maintaining the constant throttle position continuously for three hours. The termination criterion for this determination was whenever the battery system drops to 94.5 Volts. This voltage was reached after 3:02:21 for the July 8 determination; and after 2:56:15 for the July 18 determination.

\section{ACKNOWLEDGEMENTS}

Ford would like to acknowledge the support and cooperation of George Cole and Roger Richardson from INEL for their efforts in providing the technical assistance necessary to test the EVcort at CTL. Also, we would like to acknowledge Ron Schaefer and Mark Doorlag of the EPA for providing valuable information on their experiences with the EVcort in this test program. And, we would also like to acknowledge the efforts of all of the Ford personnel who contributed in the testing of the EVcort especially Dave 
Davis, Kim Donahue, Howard Love, Armando Perez, Pete Simon, Larry Thomas, Mark Weisbrod, and Doug Wright.

\section{REFERENCES}

1. "Electric Vehicle Energy Consumption and Range Test Procedure", Surface Vehicle Recommended Practice J1634, Society of Automotive Engineers, May 20, 1993.

2. "Road Load Measurement and Dynamometer Simulation Using Coastdown Techniques", Recommended Practice J1263, Society of Automotive Engineers, May, 1984.

3. Memorandum from Robert Bruetsch, Project Engineer, TDG, U.S. EPA to Karl Hellman, Chief, TDG, U.S. EPA, July 6, 1993.

4. Telecopier transmittal from George Cole, Program Manager, Electric and Hybrid Vehicles Program, INEL to Tim Webb, Certification Standards Engineer, Correlation Engineering Department, Ford Motor Company, November 16, 1993. 


\section{APPENDIX C}

Letter Report - Southwest Research Institute

C-1 

ELECTRIC "EVCORT" ROUND ROBIN TEST

\author{
USING SAE RECOMMENDED \\ PRACTICE J1634
}

\author{
BY \\ EDWARD A. BASS
}

\title{
SOUTHWEST RESEARCH INSTITUTE DEPARTMENT OF EMISSIONS RESEARCH
}

SEPTEMBER 25, 1994 


\begin{abstract}
The Evcort round robin test at SwRI resulted in a combined urban and highway range of $73.1 \mathrm{~km}$ ( 45.4 miles). The energy consumption test used $284 \mathrm{AC} \mathrm{Wh} / \mathrm{km}$ (456 AC Wh/mile) when measured with two urban and two highway cycles. The battery capacity test yielded $132 \mathrm{Ah}$ at a constant current of 47 amperes. These data were obtained with the INEL onboard computer. SwRI's laboratory data acquisition measurements were within 3\% on all measured and integrated data.
\end{abstract}

\title{
INTRODUCTION
}

Southwest Research Institute (SwRI) conducted SAE Recommended Practice J1634 tests on an Evcort electric car as an internally funded effort to participate in an industry round robin including INEL, US EPA, Ford, and California ARB. The tests were conducted at SwRI's Department of Emissions Research in August, 1994.

The test vehicle, a 1988 Ford Escort station wagon converted when new by Soleq of Chicago, Illinois, was equipped with regenerative braking, an on-board charger, and a portable INEL data acquisition system (VDAS). SwRI gathered dynamometer test data using a battery voltage tap, a battery-current shunt found on the vehicle, and other dynamometer measurements for comparison using a Labview-based data acquisition system.

\section{VEHICLE INFORMATION}

Drivetrain Configuration

Round Robin Inertia Weight Specification

Driver and Ballast Weight (on front floor)

Transmission

Tires

Battery
GE DC Shunt Motor mounted on OEM Ford Front Transaxle

4250 lbs.

289 lbs.

gear shifts:

$0-45 \mathrm{mph}$ 2nd gear (2.12:1)

45-70mph 3rd gear (1.39:1)

Arrived with a slow leak - no fluid was added

Michelin radial XGT P175/65R14, Cold Pressure Set Before Each Test: 45psi, rear tires were moved to front axle before testing

108V nominal, Sonnenschein 6-volt, lead acid modules, 7 units above the motor and 11 below rear cargo deck 

choppers operate between 400 and $2000 \mathrm{~Hz}$, $400 \mathrm{~A}$ maximum armature drive current, $225 \mathrm{~A}$ maximum regeneration current. The unit required control board repair before testing.

\section{LABORATORY EQUIPMENT}

Chassis Dynamometer Facility

Dynamometer Warm-Up/Coast-Down

Data Acquisition System
SwRI Chassis Cell No. 5 using Clayton Model ECE-50 hydrokinetic absorption unit

Twin roll, diameter $=22.0 \mathrm{~cm}$ (8.65in.)

Roll Spacing $=43.8 \mathrm{~cm}$ (17.3in.)

PWM Motor/Controller (Hitachi HFC-VWS) provides dynamometer warm-up and coast-down functions. Built in lift raises vehicle off of rolls during these operations.

SwRI EV/HEV monitoring program based on National Instruments LabView software and DAS hardware.

\section{TEST CONDITIONS AND PROCEDURES}

Road load was based on the $55 \mathrm{mph}$ to $45 \mathrm{mph}$ coast-down times. The average of six coast-down checks after the dynamometer road load adjustment was 23.15 seconds compared to the INEL measurement of 23.14 seconds. The coast-down was checked for information only between $60 \mathrm{mph}$ and $10 \mathrm{mph}$. SwRI recorded 168 seconds compared to the INEL measurement of 163 seconds. At this setting the actual load on the vehicle at $50 \mathrm{mph}$ was $5.8 \mathrm{hp}$. The inertia weight was set a $4250 \mathrm{lb}$. The accuracy of the road load data which was provided for this program has been questioned by others in the round robin program. See Reference No. 3 for a discussion of this issue. SwRI did not verify the vehicle's actual weight or road load since all laboratories in the round robin used the same values for consistency. The INEL on-site representative, Roger Richardson, provided the test weight and inertia setting information.

The test vehicle was not operating correctly when it was received by SwRI. The motor controller exhibited intermittent power loss which disabled acceleration. The problem was isolated as a cracked resistor on the control board. This repair and a tire replacement were performed before official tests began. The rear tires and wheels were installed on the front axle. No other anomalies occurred during the three tests which followed.

For all three tests, SwRI collected driving cycle test data for speed and distance, road load, battery voltage and current. Battery discharge was monitored by integrating amperehours (Ah) and watt-hours (Wh). Energy consumption data in Table 1 includes the first and second HWFET cycles. The SAE practice dictates that the first HWFET cycle be excluded from the energy calculations. Table 2 addresses this requirement. However, the combined 
efficiency ( $\mathrm{AC} \mathrm{Wh} / \mathrm{km}$ ) data is not meaningful when the first HWFET cycle is omitted. The use of both HWFET cycles (Table 1 data) should be considered.

Soak times between UDDS cycles for the energy consumption test were 10 minutes as clearly stated in the SAE document. For the range test, however, the soak time is not specified between UDDS cycles. For consistency, the same soak times (10 minutes) were used for the energy consumption and range tests at SwRI. We suggest that this be clarified in the SAE document.

Range test termination was a difficult part of the procedure, as pointed out by others (FORD, INEL references). During conduct of the Range test, SwRI observed some momentary deviations from the driving schedule on the fifth UDS test (after two HWFET cycles also), but chose to terminate at 227 seconds into the final UDS when the vehicle could not reach the minimum speed of $45 \mathrm{mph}$, as required by the procedure. The procedure states that the test must be terminated "if the vehicle cannot attain a minimum speed of $72 \mathrm{kph}$ $(45 \mathrm{mph})$ within 30 seconds after the 187 -second mark...".

Battery capacity $(\mathrm{C} / 3)$ determination was conducted, as required by section 3.2 .2 of the $\mathrm{SAE}$ procedure, by operating the vehicle with a throttle positioner on the chassis dynamometer. Figure 1 shows the current and voltage traces for this test. The oscillations at the beginning and at two other points of the test were caused by the adjustment of the throttle positioner to maintain the $\mathrm{C} / 3$ discharge rate near the target of 46 amperes. The dynamometer and drivetrain were not warmed up in preparation for this test. We believe this would have been helpful to allow less adjustment of the throttle at the beginning of the test. Dynamometer and drivetrain warm-up could have been done with the motoring capability of the chassis dynamometer. The discharge test was terminated at $1.75 \mathrm{~V} / \mathrm{cell}$ as is standard practice for lead-acid batteries.

Laboratory ambient conditions were recorded as required by SAE J1634. Test cell temperature for all tests was maintained between 74 and 75 degrees Fahrenheit. The barometer varied between 29.19 and $29.24 \mathrm{in}$. $\mathrm{Hg}$ at the laboratory, where the altitude is 810 $\mathrm{ft}$ above sea level.

\section{TEST RESULTS}

Tables 1, 2, 3, and 4 summarize the results of the Energy Consumption, Range, and Battery Capacity Tests. Results from both data acquisition systems are included, where available. The percent difference between SwRI and VDAS data was calculated based on the average of the two measurements. The discharge energy measured by SwRI was consistently about two percent higher than the VDAS measurement. This could be due to the use of two different battery current shunts for each data acquisition system. SwRI did not have an opportunity to remove and calibrate either shunt on the vehicle. The distance measured by the two systems differed by about three percent. SwRI used a 60-tooth gear on the dynamometer calibrated by a strobe tachometer. The VDAS system used the vehicle's transmission speedometer gear and always measured higher than the SwRI system. Another possibility for error exists from wheel slippage between the tires and the dynamometer. 
J1634 suggests a separate recording of regenerative braking energy. This data was not separately integrated in the VDAS and SwRI data acquisition systems. It could be derived from the raw data in a spreadsheet analysis. This report, however, has not included this analysis.

TABLE 1. ENERGY CONSUMPTION TEST

\begin{tabular}{|c|c|c|c|}
\hline & VDAS & $\overline{\text { SWRI }}$ & \% Differ. \\
\hline Test Date & & $8 / 18 / 94$ & \\
\hline Test Start Time & & 13:19 & \\
\hline Distance Measured During Test, km (mi) & $58.7(36.5)$ & $57.3(35.6)$ & 2.5 \\
\hline Discharge, DC Ah & 96 & 97.7 & 1.8 \\
\hline Discharge, DC kWh & 9.33 & 9.51 & 1.9 \\
\hline Discharge Efficiency, DC Wh/km (Wh/mi) & $159(256)$ & $166(267)$ & 4.2 \\
\hline Charge, DC Ah & 103.9 & & \\
\hline Charge, AC kWh & 16.65 & & \\
\hline Charge Time, $h$ & 12.9 & & \\
\hline Overall Efficiency, AC Wh/km (Wh/mi) & $284(456)$ & & \\
\hline
\end{tabular}

TABLE 2. ENERGY CONSUMPTION TEST EXCLUDING HWFET CYCLE NO. 1

\begin{tabular}{|c|c|c|c|}
\hline & VDAS & SwRI & $\%$ Differ. \\
\hline Test Date & & $8 / 18 / 94$ & \\
\hline Test Start Time & & $13: 19$ & \\
\hline Distance Measured During Test, $\mathrm{km}$ (mi) & $41.75(25.94)$ & $40.80(25.35)$ & 2.3 \\
\hline Discharge, DC Ah & 71 & 71.9 & 1.3 \\
\hline Discharge, DC kWh & 6.88 & 7.05 & 2.4 \\
\hline Discharge Efficiency, DC Wh/km (Wh/mi) & $165(265)$ & $173(278)$ & 4.7 \\
\hline Charge, DC Ah & 103.9 & & \\
\hline Charge, AC kWh & 16.65 & & \\
\hline Charge Time, $\mathrm{h}$ & 12.9 & & \\
\hline Overall Efficiency, AC Wh/km (Wh/mi) & $399(642)$ & & \\
\hline
\end{tabular}


TABLE 3. RANGE TEST

\begin{tabular}{|c|c|c|c|}
\hline & VDAS & SwRI & $\%$ Diff. \\
\hline Test Date & & $8 / 19 / 94$ & \\
\hline Test Start Time & & $08: 35$ & \\
\hline Distance Measured During Test, km (mi) & $73.10(45.40)$ & $70.94(44.08)$ & 3.0 \\
\hline Discharge, DC Ah & 124 & 126 & 1.6 \\
\hline Discharge, DC kWh & 11.9 & 12.2 & 2.5 \\
\hline Discharge Efficiency, Wh/km (Wh/mi) & $163(262)$ & $172(278)$ & 5.9 \\
\hline Charge, DC Ah & 130.1 & & \\
\hline Charge, AC kWh & 20.63 & & \\
\hline Charge Time, $\mathrm{h}$ & 15.9 & & \\
\hline Combined Efficiency, AC Wh/km (Wh/mi) & $282(454)$ & & \\
\hline
\end{tabular}

TABLE 4. BATTERY CAPACITY TEST (TERMINATED AT 1.75V/CELL)

\begin{tabular}{|c|c|c|c|}
\hline & VDAS & SwRI & $\%$ Diff. \\
\hline Test Date & & $8 / 22 / 94$ & \\
\hline Test Start Time & & $14: 11$ & \\
\hline Distance Measured During Test, km (mi) & $145.2(90.23)$ & $141.2(87.75)$ & 2.8 \\
\hline Discharge, DC Ah & 132 & 135 & 2.2 \\
\hline Discharge, DC kWh & 13.99 & 14.33 & 2.4 \\
\hline Discharge Efficiency, Wh/km (Wh/mi) & $96.3(155)$ & $101(163)$ & 5.0 \\
\hline Charge, DC Ah & 142 & & \\
\hline Charge, AC kWh & 22.58 & & \\
\hline Charge Time, $h$ & 16.08 & & \\
\hline Combined Efficiency, AC Wh/km (Wh/mi) & $156(250)$ & & \\
\hline
\end{tabular}

\section{CONCLUSIONS AND RECOMMENDATIONS}

1. The Energy Consumption test should include HWFET cycle \#1. The original reason for conducting one unmeasured HWFET on heat engine vehicles was to precondition 
or warm up the vehicle. Since warm up time constants on electric vehicles are much shorter, and the SAE practice requires two UDDS cycles before the HWFET cycles, the vehicle should be conditioned already when it runs the first HWFET cycle. Furthermore, the combined efficiency, calculated from recharge energy and distance measured, is meaningful only when accounting for all the driving cycles conducted.

2. Soak times in the range test are not as fully specified as they are for the energy consumption test. These two tests should be consistent, with 10-minute soaks, to minimize lab difficulty.

3. Range test termination criteria are not clear and are difficult to implement. The minimum speed of $45 \mathrm{mph}$ at the 217 -second point in the UDDS test was a workable termination point. The same speed minimum is specified already for the HWFET cycle.

4. The INEL and SwRI data acquisition systems agreed within $3 \%$ on all measured and integrated parameters.

\title{
ACKNOWLEDGEMENTS
}

The SwRI Internal Research program and the Department of Emissions Research provided the funding for this study. SwRI gratefully acknowledges the organizers and participants in the round robin test program:

\author{
U.S. Department of Energy \\ Arizona Public Service \\ Idaho National Engineering Laboratory \\ Ford Correlation Engineering \\ U.S. Environmental Protection Agency \\ California Air Resources Board
}

\section{REFERENCES}

1. "Performance Testing and System Evaluation of the Soleq Evcort Electric Vehicle", R.L. Crumley, R.D. McDowall, J.E. Hardin, A.F. Burke, EG\&G Idaho, U.S. D.O.E ID-10232, March 1989

2. "Electric Vehicle Energy Consumption and Range Test Procedure" SAE J1634, Issued 1993-05-20

3. "Electric Vehicle Round Robin Testing Using SAE Recommendation Practice J1634", Michael J. Fuher, Ford Motor Company Certification Test Laboratory, August 1994

4. "INEL Experience with SAE J1634 Test Procedure for Electric Vehicles", A.F. Burke, Presented at the SAE Hybrid Electric Vehicle Test Procedure Task Force, January 1993 
APPENDIX A

COAST DOWN CURVE

C-11 



\section{EVCORT COAST DOWN AT SWRI $60-10 \mathrm{MPH}$ Ind. $\mathrm{HP}=3.3 \mathrm{Act} . \mathrm{HP}=5.8$}

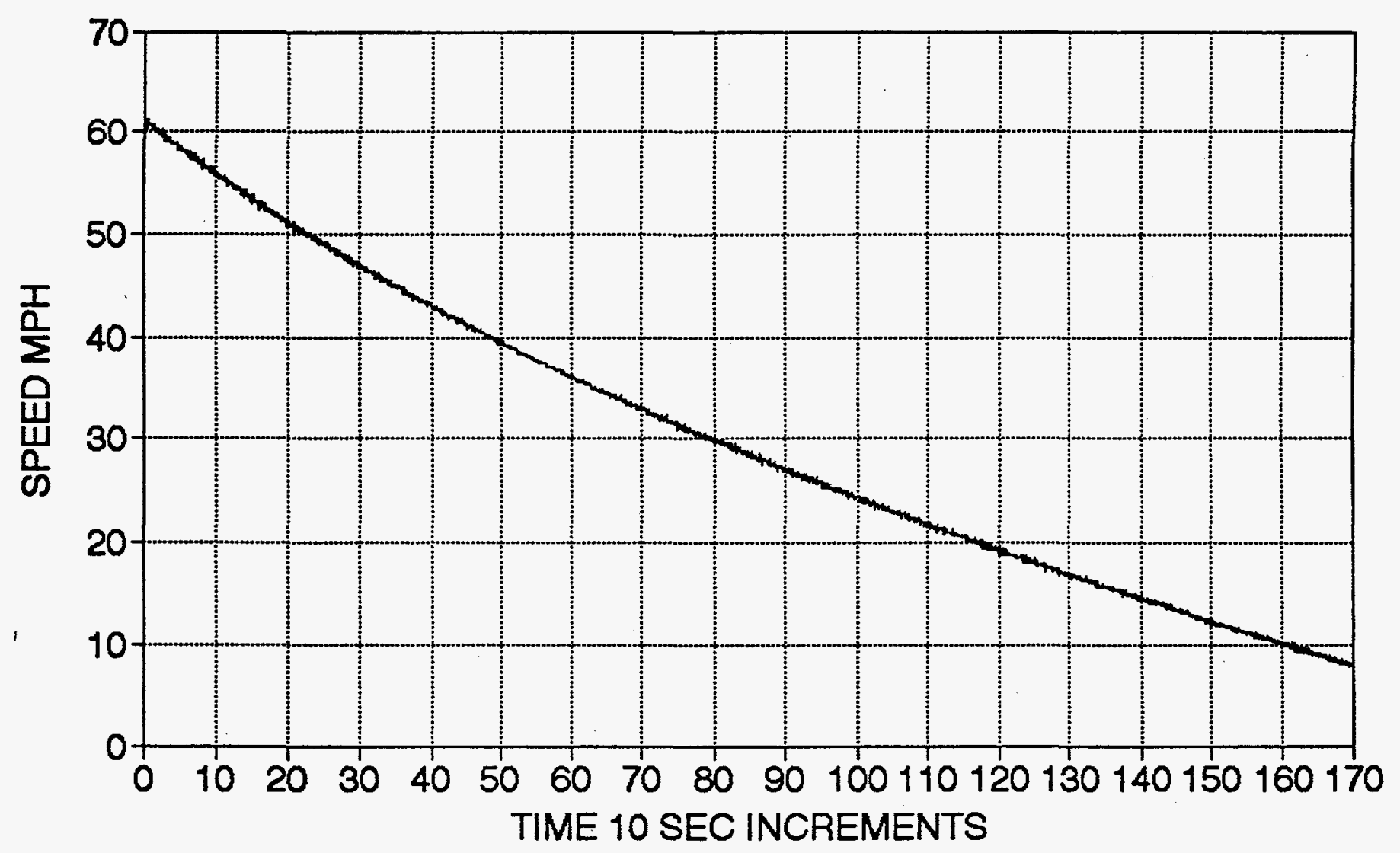


;

, 
APPENDIX B

C/3 DISCHARGE CURVE 
, 


\section{EVcort C/3 TEST}

Avg. Current $=46.8$ amps

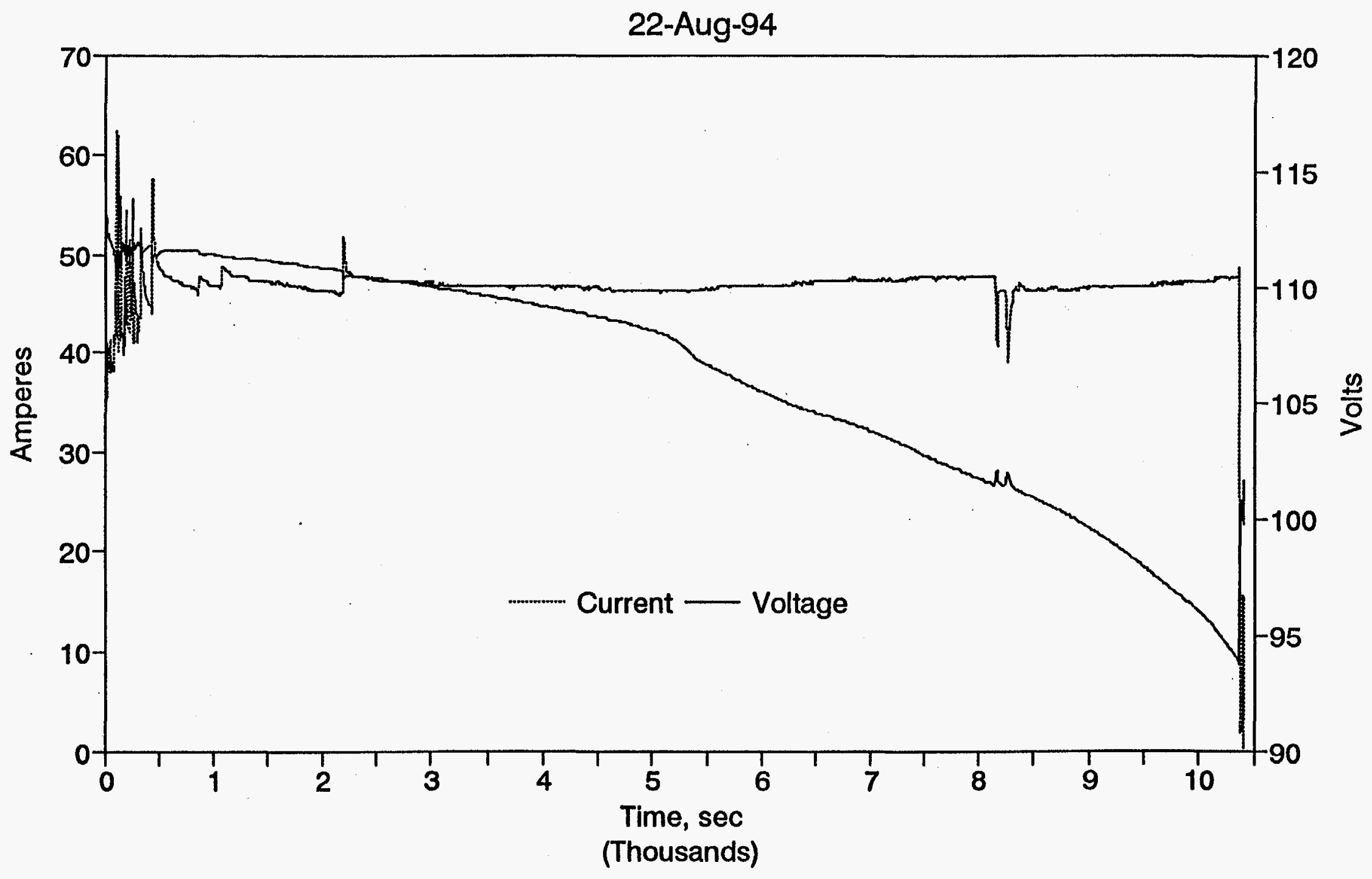




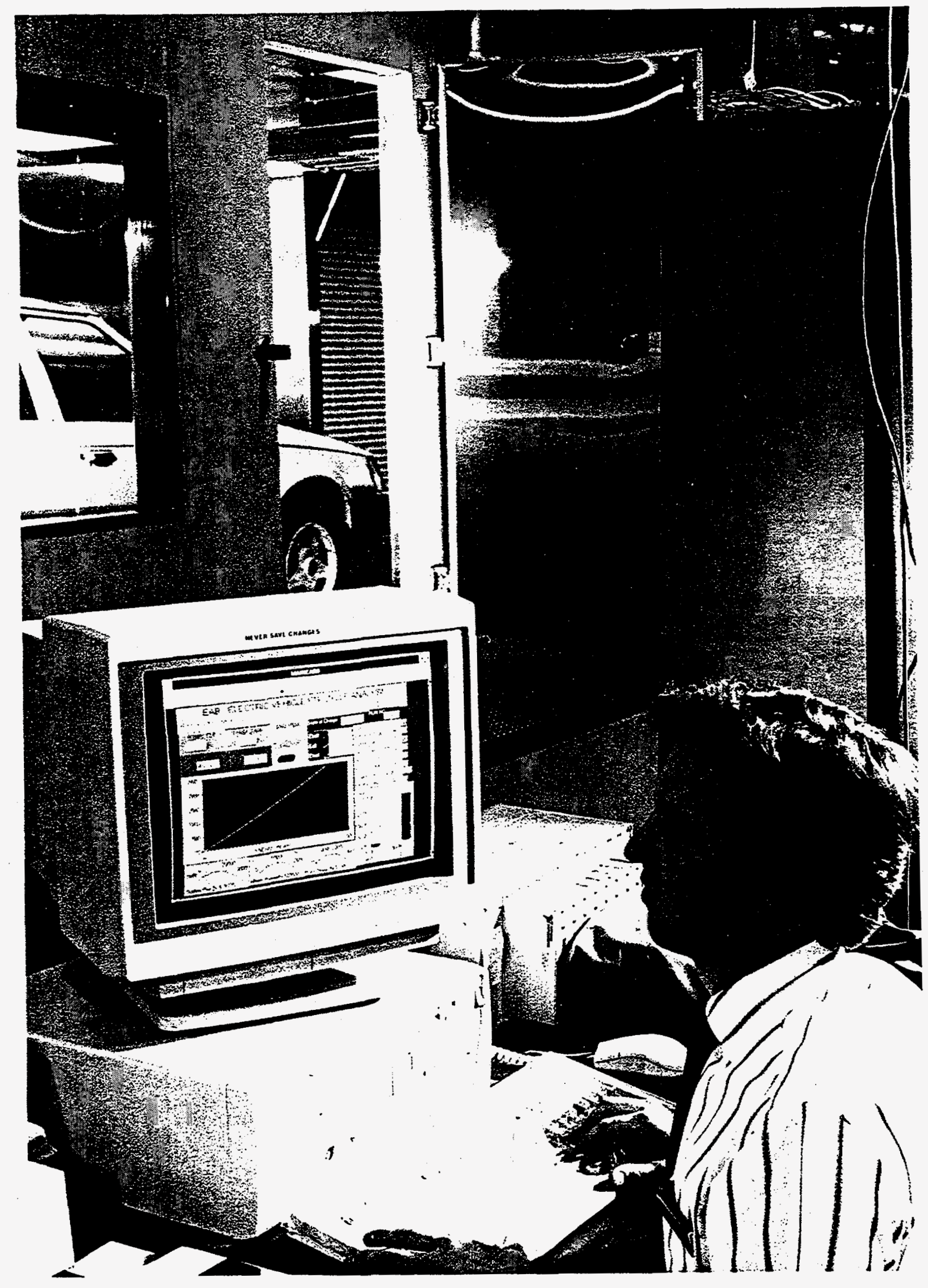

